\title{
Continuous Postnatal Neurogenesis Contributes to Formation of the Olfactory Bulb Neural Circuits and Flexible Olfactory Associative Learning
}

\author{
Masayuki Sakamoto, ${ }^{1,2}$ Nao Ieki, ${ }^{3}$ Goichi Miyoshi, ${ }^{4}$ Daisuke Mochimaru, ${ }^{3}$ Hitoshi Miyachi, ${ }^{1}$ Tetsuya Imura, ${ }^{5}$ \\ Masahiro Yamaguchi, ${ }^{3}$ Gord Fishell, ${ }^{4}$ Kensaku Mori, ${ }^{3}$ Ryoichiro Kageyama, ${ }^{1,6,7}$ and Itaru Imayoshi ${ }^{1,7,8,9}$ \\ ${ }^{1}$ Institute for Virus Research, Kyoto University, Kyoto 606-8507, Japan, ${ }^{2}$ Kyoto University Graduate School of Biostudies, Kyoto 606-8502, Japan, ${ }^{3}$ Graduate \\ School of Medicine, University of Tokyo, Tokyo 113-0033, Japan, ${ }^{4}$ New York University Neuroscience Institute, Department of Physiology and \\ Neuroscience, Smilow Research Center, New York University School of Medicine, New York, New York 10016, ${ }^{5}$ Department of Basic Pathology, Fukushima \\ Medical University School of Medicine, Fukushima 960-1295, Japan, ${ }^{J}$ Japan Science and Technology Agency, Core Research for Evolutional Science and \\ Technology, Kyoto 606-8507, Japan, ${ }^{7}$ World Premier International Research Initiative-Institute for Integrated Cell-Material Sciences, Kyoto University, \\ Kyoto 606-8501, Japan, ${ }^{8}$ Hakubi Center, Kyoto University, Kyoto 606-8507, Japan, and ${ }^{9}$ Japan Science and Technology Agency, Precursory Research for \\ Embryonic Science and Technology, Kyoto 606-8507, Japan
}

The olfactory bulb $(\mathrm{OB})$ is one of the two major loci in the mammalian brain where newborn neurons are constantly integrated into the neural circuit during postnatal life. Newborn neurons are generated from neural stem cells in the subventricular zone (SVZ) of the lateral ventricle and migrate to the $\mathrm{OB}$ through the rostral migratory stream. The majority of these newborn neurons differentiate into inhibitory interneurons, such as granule cells and periglomerular cells. It has been reported that prolonged supply of newborn neurons leads to continuous addition/turnover of the interneuronal populations and contributes to functional integrity of the $\mathrm{OB}$ circuit. However, it is not still clear how and to what extent postnatal-born neurons contribute to $\mathrm{OB}$ neural circuit formation, and the functional role of postnatal neurogenesis in odor-related behaviors remains elusive. To address this question, here by using genetic strategies, we first determined the unique integration mode of newly born interneurons during postnatal development of the mouse OB. We then manipulated these interneuron populations and found that continuous postnatal neurogenesis in the SVZ-OB plays pivotal roles in flexible olfactory associative learning and memory.

Key words: dentate gyrus; hippocampus; learning; neural stem cells; neurogenesis; olfactory bulb

\section{Introduction}

The rodent olfactory bulb (OB) has a unique neural circuit consisting predominantly of interneurons. Unlike most other central nervous system (CNS) regions, in the OB, inhibitory interneurons far outnumber principal neurons by at least 50:1 (Isaacson

Received Feb. 17, 2014; revised March 12, 2014; accepted March 18, 2014.

Author contributions: M.S., G.F., K.M., R.K., and I.I. designed research;M.S., N.I, G.M., D.M., H.M., T.I., M.Y., G.F., and I.I. performed research; M.S., G.M., D.M., H.M., T.I., M.Y., G.F., R.K., and I.I. contributed unpublished reagents/ analytic tools; M.S. and I.I. analyzed data; M.S. and I.I. wrote the paper.

This work was supported by the Ministry of Education, Culture, Sports, Science and the Technology of Japan and Japan Science and Technology Agency research grants as well as the Japan Society for the Promotion of Science for Young Scientists research fellowships to M.S. and the Japan Science and Technology Agency Precursory Research for Embryonic Science and Technology program to I.I. This study was also supported in part by a grant from the Mitsubishi Foundation. We thank the following researchers for kindly sharing their reagents: Shigeyoshi Itohara (NSE-LoxP-DTA mice), Shigetada Nakanishi (EGFP-TeNT cDNA), Jan Stenman (pBSApBpACAGftILn plasmid), Andy McMahon (pRosa26PAS plasmid), Toshiaki Nakashiba and Susumu Tonegawa (SypGFP-IRES-mCherry-VAMP2 Moloney viral vector), Takahiko Matsuda (Tc-1 embryonic stem cells), and Masaharu 0gawa (Anti-Reelin antibody). We are also grateful to Adi Mizrahi for discussion.

The authors declare no competing financial interests.

Correspondence should be addressed to Dr. Itaru Imayoshi, Institute for Virus Research, Kyoto University, Shogoin-Kawahara, Sakyo-ku, Kyoto 606-8507, Japan. E-mail: iimayosh@virus.kyoto-u.ac.jp.

M. Sakamoto's present address: Department of Biological Sciences, Columbia University, New York, NY 10027

DOI:10.1523/JNEUROSCI.0674-14.2014

Copyright $\odot 2014$ the authors $\quad 0270-6474 / 14 / 345788-12 \$ 15.00 / 0$ and Strowbridge, 1998; Shepherd and Greer, 2004; Egger and Urban, 2006). In contrast, in neocortex, the ratio of inhibitory to principal neurons is $\sim 1: 5$ (Anderson et al., 1994). Furthermore, integration of $\mathrm{OB}$ interneurons continues long after the sensory neuron axons and principal neurons have established their mature connectivity. Although most neurons comprising the mammalian CNS are produced during embryonic development, a large proportion of the interneurons in the $\mathrm{OB}$ are generated during postnatal life (Lazarini and Lledo, 2011; BretonProvencher and Saghatelyan, 2012). In the postnatal brain, neurons are generated from neural stem cells (NSCs) in the subventricular zone (SVZ) of the lateral ventricle (LV). Newborn neurons migrate to the $\mathrm{OB}$ through the rostral migratory stream (RMS), and the majority of them mature into inhibitory interneurons (Lledo et al., 2006), although a small number of newborn neurons differentiate into glutamatergic neurons (Brill et al., 2008; Sequerra et al., 2010; Winpenny et al., 2011). The two most numerous types of inhibitory $\mathrm{OB}$ interneurons are granule cells (GCs) and periglomerular cells (PGCs) (Shepherd and Greer, 2004; Yamaguchi et al., 2013). The number of GCs is $\sim 1$ order larger than that of PGCs. Both GCs and PGCs are continually generated postnatally and even in adulthood. However, despite ex- 
tensive studies with $\left[{ }^{3} \mathrm{H}\right]$-thymidine, BrdU, or retroviruses, how these postnatal-born neurons integrate into $\mathrm{OB}$ neural circuits is still unclear, partly because $\left[{ }^{3} \mathrm{H}\right]$-thymidine and $\mathrm{BrdU}$ can be administered only for restricted periods, and injections of retroviruses into the brain infect only small populations. Thus, postnatal development of the $\mathrm{OB}$ inhibitory network is based on estimations from lineage-tracing experiments of limited populations (Bayer, 1983; Gould, 2007).

Strikingly, neurogenesis in the SVZ of the LV occurs throughout adulthood (Imayoshi et al., 2011; Ming and Song, 2011). This ongoing supply of adult-born interneurons leads to continuous turnover/ addition of the interneuronal populations and structural integrity of the OB circuit (Kohwi et al., 2007; Ninkovic et al., 2007; Imayoshi et al., 2008; Adam and Mizrahi, 2011; Breton-Provencher and Saghatelyan, 2012). However, the significance of postnatal neurogenesis and turnover of interneurons on olfaction-dependent behaviors is still unclear (Lledo et al., 2006; Lazarini and Lledo, 2011; BretonProvencher and Saghatelyan, 2012).

To understand information processing in the $\mathrm{OB}$, it is important to reveal how the newly generated OB interneurons are integrated into $\mathrm{OB}$ circuitry during postnatal development. To address these issues, we used genetic approaches that specifically and efficiently label postnatal NSCs and newly formed neurons, and analyzed how continuous neurogenesis contributes to the formation of inhibitory neural networks in the postnatal OB. We also used intersectional strategies to achieve precise genetic targeting of newly born $\mathrm{OB}$ neurons. Our fate mapping efforts were complemented with specific loss-of-function strategies coupled with behavioral odor discrimination tasks, and conducted to examine the functionality of the newly formed neurons.

\section{Materials and Methods}

Breeding and tamoxifen treatment of mice. mGFAP-Cre, Nestin-CreER ${ }^{T 2}$, and Dlx5/6-Flpe transgenic mouse strains were described previously (Garcia et al., 2004; Imayoshi et al., 2008; Miyoshi et al., 2010). These strains were crossed with the following reporter/effector strains: $R 26 R-$ CAG-LoxP-mTFP1, R26R-LoxP-ECFP, RCE:FRT (R26R-CAG-Frt-EGFP), RCE:dual (R26R-CAG-LoxP-Frt-EGFP), neuron-specific enolase (NSE)LoxP-DTA, R26R-CAG-LoxP-Frt-EGFP-TeNT, and VGLUT1-LoxPTeNT (I.I. and R.K., manuscript in preparation) (Srinivas et al., 2001; Imayoshi et al., 2008; Miyoshi et al., 2010; Imayoshi et al., 2012). Double or triple transgenic mice were identified by PCR as described previously. Mice were housed in a room with $12 \mathrm{~h}$ light/dark cycle (lights on at 6:00 A.M.). All animals were handled in accordance with the Kyoto University Guide for the Care and Use of Laboratory Animals. CreER ${ }^{\mathrm{T} 2}$ activation in $\mathrm{P} 1$ pups was triggered by tamoxifen ( $30 \mu \mathrm{l}$ i.p. of $20 \mathrm{mg} / \mathrm{ml}$ stock in corn oil; Sigma). For CreER ${ }^{\mathrm{T} 2}$ activation in P21 mice, one shot of $200 \mu \mathrm{l}$ of tamoxifen stock was administered orally.

Generation of R26R-CAG-LoxP-Frt-EGFP-TeNT strain. The R26RCAG-LoxP-Frt-EGFP-TeNT knock-in vector contains a splice acceptor sequence-puromycin resistance gene, a CAG promoter, a floxed primary stop cassette containing three polyadenylation sequences ( $\mathrm{pA}$ ) from SV40pA, a Frt-flanked stop cassette containing three pA sequences (SV40pA-TKpA-SV40pA), and EGFP-TeNT-SV40pA. To generate the final targeting vector, the above transgene construct was introduced into the PacI/AscI site of the pRosa26PAS plasmid (Mao et al., 2005; Stenman et al., 2008). The resulting vector contains $5^{\prime}$ and $3^{\prime}$ homology arms of 1.1 and $4.1 \mathrm{kbp}$, respectively, which target the construct to the Xbal site of intron 1 at the Rosa26 locus. The detailed cloning strategy and complete sequence of the plasmids are available on request.

The targeting vector was linearized with SwaI and electroporated into the 129S6/SvEvTac-derived Tc-1 embryonic stem cells; puromycin-resistant clones were selected. Genomic DNA from drugresistant cells was screened by PCR for homologous recombination at the Rosa26 locus, using the primers Rosa26-5' armFlanking (5'CCTAAAGAAGAGGCTGTGCTTTGG-3') and Rosa26-SA (5' -CATCA
AGGAAACCCTGGACTACTG-3'), which amplified a 1.2 -kbp product. Southern blot hybridization on EcoRV-digested genomic DNA was used to confirm homologous recombination at the $5^{\prime}$-end using a $0.14 \mathrm{kbp}$ probe located outside of the $5^{\prime}$-homology arm. The probe was generated by EcoRI and HindIII digestion of the pRosa26 5'probe plasmid. The targeted and wild-type alleles produced products of 11.5 and $4.9 \mathrm{~kb}$, respectively. Chimeric mice were produced from two successfully targeted ES cell clones by aggregation with C57BL/6J embryos. Germline transmission of the targeted allele was assessed by EGFP-TeNT PCR with the primers (5'-CGAGAAGCGCGATCACATGGTCCTG-3') and (5'TATCTAATAAGGCTTCACCTGCTAC-3'), which generate a 413 bp product. The chimeric mice and their descendants were crossed with wild-type C57BL/6J mice five times before the analysis.

The R26R-CAG-LoxP-Frt-EGFP-TeNT strain and its derivatives were deposited at the RIKEN Bioresource Center (http://www.brc.riken. $\mathrm{jp} / \mathrm{lab} / \mathrm{animal} / \mathrm{en} /$ ) under the following reference numbers: B6;129S6Gt(ROSA)26Sortm1(CAG-EGFP/TeNT)Imayo (RBRC05153), B6;129S6Gt(ROSA)26Sortm1.1(CAG-EGFP/TeNT)Imayo (RBRC05154), and B6; 129S6-Gt(ROSA)26Sortm1.2(CAG-EGFP/TeNT)Imayo (RBRC05155). Live mice, cryopreserved embryos, and sperm of the deposited knock-in strains are available from the RIKEN Bioresource Center.

Virus preparation and injection. Moloney viral particles carrying SypGFP-IRES-mCherry-VAMP2 were prepared as described previously (Nakashiba et al., 2012). Mice and their control littermates (12 weeks old) were anesthetized with ketamine $(22.5 \mathrm{mg} / \mathrm{kg})$, and $0.4 \mu \mathrm{l}$ of virus concentrate was stereotaxically injected to SVZ/LV. The stereotaxic coordinate was $0.0 \mathrm{~mm}$ anterior from bregma, $1.7 \mathrm{~mm}$ lateral from the midline, and 1.8-2.6 mm ventral from the brain surface.

Tissue preparation and immunohistochemistry. Pups and adult mice were deeply anesthetized with sodium pentobarbital $(50 \mathrm{mg} / \mathrm{kg}$ i.p.) and transcardially perfused with $50 \mathrm{ml}$ of PBS and $50 \mathrm{ml}$ of $4 \% \mathrm{PFA} / \mathrm{PBS}, \mathrm{pH}$ 7.2. Brains were postfixed in the perfusing solution overnight at $4^{\circ} \mathrm{C}$ and then cryoprotected for $24 \mathrm{~h}$ in $30 \%$ sucrose in PBS. Brains were embedded in OCT compound (Sakura Finetek) and frozen at $-80^{\circ} \mathrm{C}$.

Cryostat sections ( $16 \mu \mathrm{m}$ thick) were incubated in 5\% normal goat serum and $0.1 \%$ Triton X-100/PBS at room temperature for $1 \mathrm{~h}$, incubated with primary antibodies diluted in $0.1 \%$ Triton X-100/PBS containing $1 \%$ normal goat serum overnight at $4^{\circ} \mathrm{C}$, washed with PBS, and then incubated with secondary antibodies conjugated to Alexa-405, Alexa-488, Alexa-594, or Alexa-633 (1:200, Invitrogen) for $1 \mathrm{~h}$ at room temperature. The sections were mounted with Fluormount-G (Southern Biotech) and photographed with an LSM510 confocal laser-scanning microscope (Zeiss).

The following primary antibodies (final dilution and source) were used: rat anti-BrdU (1:50; Oxford Biotech), rabbit anti-DsRed (1:400; Clontech), rabbit anti-GFP (1:400; Invitrogen), rat anti-GFP (1:400; Nacalai), mouse anti-NeuN (1:400; Millipore), rabbit anti-5T4 (1:1000; Imamura et al., 2006), rabbit anti-Reelin (1:100; kindly provided from Dr. Masaharu Ogawa), and rabbit anti-VAMP2 (1:500; Synaptic Systems), mouse anti-TH (1:1000; Millipore), mouse anti-Calbindin-D28K (1:1000; Swant), and mouse anti-Calretinin (1:1000; Swant).

Organization of tissues for histological quantification. We analyzed at least three mice at all time points. Serial sections ( $16 \mu \mathrm{m}$ thick) were cut from the anterior to the posterior ends of the $\mathrm{OB}$, and a different 1-in-10 series was used for each of the quantifications. Four regions (dorsal, medial, ventral, and lateral) were selected from the granule cell layer (GCL) or periglomerular cell layer (PGL) of the OB in each section, including GCLs/PGLs throughout the deep to the superficial extent. Fluorescent images were taken on a LSM510 confocal laser scanning microscope using a $20 \times$ objective.

Quantification of mTFP1/ECFP-labeled granule cells (GCs) and periglomerular cells (PGCs) in the OB. mTFP1/ECFP-labeled, newly generated GCs/PGCs were analyzed on sections throughout the anterior-posterior extent of the GCL/PGL of the OB, and their average scores were determined. Average scores from the same genotype groups were pooled to determine the total average and SD, and the proportion of mTFP1/ECFP labeling of marker (NeuN, CalR, CalB, or TH)-positive GCs/PGCs was determined. 
Estimation of the total cell number of $O B$ GCs during postnatal development. P7, P14, P21, $\mathrm{P} 35$, and $\mathrm{P} 60 \mathrm{C} 57 \mathrm{BL} / 6 \mathrm{~J}$ male mice were obtained from Japan SLC. Sections were stained with anti-NeuN antibody, and the volume of the GCL in the OB of each stained section was quantified using Zeiss software. The mean GCL volume in one section was calculated, and the total volume was determined by multiplying the mean value by the total number of sections. Neuronal density was assessed in the $\mathrm{OB}$ (as described above) of each anti-NeuN antibody-stained section. Sections from four different anterior/posterior levels at regularly spaced intervals were examined. The numbers of NeuN-positive cells were counted on $z$-stacked confocal images, and the mean numbers of cells within the counting area were calculated. The total numbers of GCs in the OB were obtained by multiplying the GCL volume by the neuronal cell-density. For statistical analysis, one-way ANOVA with the post hoc Tukey's test was done for multiple comparisons.

Behavioral tests. All behavioral tests were conducted with 3-month-old male control $(n=6)$ and mutant $(n=6)$ mice, except for the experiments in Figure 8.

In the analysis of OB-mutant ( $m G F A P-C r e$; Dlx5/6-Flpe;R26R-CAG-LoxP-Frt-EGFP-TeNT triple transgenic) mice, mGFAP-Cre;R26RCAG-LoxP-Frt-EGFP-TeNT double transgenic mice were used as control. No apparent behavioral differences were observed between control and wild-type littermate mice.

In the analysis of postnatal neurogenesismutant mice, $4 \mathrm{mg}$ of tamoxifen in corn oil $(n=9)$ or corn oil alone $(n=9)$ was orally administered to P21 Nestin-CreER ${ }^{T 2}$;NSELoxP-DTA double transgenic mice. Behavioral analysis was started from P35. Corn oil-treated Nestin-CreER ${ }^{T 2}$;NSE-LoxP-DTA double transgenic mice were used as control. Previously, we also analyzed two other control mouse groups (oil-treated Nestin-CreER ${ }^{T 2}$ mice and tamoxifen-treated Nestin-CreER ${ }^{T 2}$ mice) and did not observe any significant differences in behavioral tests between these and the oil-treated Nestin-CreER ${ }^{T 2}$;NSE-LoxP-DTA (Imayoshi et al., 2008).

Behavioral analyses of dentate gyrus (DG)mutant (mGFAP-Cre;VGLUT1-LoxP-TeNT double transgenic) mice were conducted by using 3-month-old mutants and their wild-type littermates. No behavioral abnormalities were observed in the mGFAP-Cre and VGLUT1-LoxP-TeNT single transgenic mice (I.I. and R.K., manuscript in preparation).

Habituation-dishabituation test. This experiment was performed as previously described (Imayoshi et al., 2008). Mice were habituated to a cage $(20 \times 15 \times 13 \mathrm{~cm})$, and then a sheet of filter paper $(2 \times 2 \mathrm{~cm})$ with $20 \mu \mathrm{l}$ of the first odor was presented for $3 \mathrm{~min}$. This procedure was repeated three times with $15 \mathrm{~min}$ intervals. On the fourth trial, filter paper with $20 \mu \mathrm{l}$ of the second odor was presented for $3 \mathrm{~min}$. Nasal contacts with the filter paper within $1 \mathrm{~mm}$ distance were judged as "investigating." Investigation time during a 3 min test period was measured. For statistical analysis, Student's $t$ test was done between sessions 3 and 4. Odors were used as follows: mineral oil (Sigma), basil (1:10 dilution in mineral oil, Hasegawa), and peppermint ( $1: 10$ dilution in mineral oil, Hasegawa).

Olfactory associative learning and memory test with reward-reversal paradigm. This task was performed as previously described with minor mod-
Table 1. Proportions of mTFP1/NeuN-labeled GCs in the OB of mGFAP-Cre;R26R-CAGLoxP-mTFP1 double transgenic mice

\begin{tabular}{crrrrrr}
\hline & \multicolumn{2}{l}{ Percentage of mTFP ${ }^{+} /$NeuN $^{+}$cells \pm SD } & \multirow{2}{*}{$\begin{array}{l}\text { No. of cells } \\
\text { analyzed }\end{array}$} \\
\cline { 2 - 6 } Age & \multicolumn{1}{c}{ Dorsal } & \multicolumn{1}{c}{ Medial } & \multicolumn{1}{c}{ Ventral } & \multicolumn{1}{l}{ Lateral } & \multicolumn{1}{l}{ Whole } & \\
\hline GCL & & & & & & \\
P7 & $7.9 \pm 3.5$ & $6.6 \pm 2.9$ & $7.3 \pm 2.6$ & $7.8 \pm 4.7$ & $7.4 \pm 3.4$ & 9371 \\
P28 & $55.1 \pm 1.2$ & $55.0 \pm 1.2$ & $55.8 \pm 3.9$ & $52.8 \pm 6.0$ & $54.6 \pm 2.5$ & 10,978 \\
P90 & $74.0 \pm 3.7$ & $73.0 \pm 2.2$ & $68.1 \pm 1.0$ & $68.4 \pm 3.6$ & $70.9 \pm 2.1$ & 14,367 \\
Outer GCL & & & & & & \\
P7 & $11.0 \pm 0.6$ & $7.6 \pm 1.1$ & $7.1 \pm 1.4$ & $9.6 \pm 1.4$ & $8.8 \pm 0.5$ & 3103 \\
P28 & $37.3 \pm 5.4$ & $34.3 \pm 0.7$ & $34.4 \pm 6.0$ & $30.2 \pm 3.2$ & $34.1 \pm 3.0$ & 3481 \\
P90 & $46.1 \pm 2.0$ & $38.6 \pm 4.8$ & $41.6 \pm 3.1$ & $35.5 \pm 5.1$ & $40.5 \pm 3.2$ & 3351 \\
\hline
\end{tabular}


Table 2. Proportions of ECFP-labeled GCs in the OB of P1-tamoxifen-treated NestinCreER $^{T 2} ;$ R26R-LoxP-ECFP double transgenic mice

\begin{tabular}{|c|c|c|c|c|c|c|}
\hline \multirow[b]{2}{*}{ Age } & \multicolumn{5}{|c|}{ Percentage of ECFP ${ }^{+} /$NeuN $^{+}$cells \pm SD } & \multirow{2}{*}{$\begin{array}{l}\text { No. of cells } \\
\text { analyzed }\end{array}$} \\
\hline & Dorsal & Medial & Ventral & Lateral & Whole & \\
\hline \multicolumn{7}{|l|}{$\mathrm{GCL}$} \\
\hline P7 & $8.3 \pm 0.4$ & $9.1 \pm 1.6$ & $8.9 \pm 1.8$ & $8.6 \pm 2.1$ & $8.7 \pm 1.4$ & 10,270 \\
\hline P28 & $61.4 \pm 5.9$ & $62.0 \pm 4.3$ & $62.6 \pm 4.1$ & $61.6 \pm 7.0$ & $61.9 \pm 4.6$ & 11,266 \\
\hline P90 & $75.8 \pm 0.9$ & $78.0 \pm 1.7$ & $75.0 \pm 3.7$ & $77.6 \pm 1.5$ & $76.6 \pm 1.0$ & 15,717 \\
\hline \multicolumn{7}{|c|}{ Outer GCL } \\
\hline P7 & $8.4 \pm 3.1$ & $8.3 \pm 2.9$ & $8.1 \pm 2.9$ & $7.1 \pm 3.6$ & $8.0 \pm 3.4$ & 3495 \\
\hline P28 & $49.3 \pm 1.4$ & $41.1 \pm 8.9$ & $41.0 \pm 8.5$ & $39.4 \pm 1.8$ & $42.7 \pm 4.6$ & 3113 \\
\hline P90 & $50.7 \pm 2.1$ & $47.4 \pm 2.7$ & $51.0 \pm 5.0$ & $45.6 \pm 2.2$ & $48.6 \pm 1.6$ & 2709 \\
\hline
\end{tabular}

(+)-Carvone (6.4M, Sigma). On days 5-8, the sugar reward was associated with $(-)$-Carvone (6.4M, Sigma). On days $9-12$, the sugar reward was again associated with $(+)$-Carvone. On days $5-12$, the probe test was conducted without the sugar reward before each training.

Mouse behavior was recorded with a digital video camera. The time (seconds) spent digging for each odorant was measured during the $4 \mathrm{~min}$ probe tests. Differences in behavior (digging time) between the mutant and control mice were assessed with two-way repeated-measures ANOVA, and $p$ values $<0.05$ indicated significant differences.

Statistical analysis. Statistical analyses were performed with Prism 6.0 software (GraphPad). $p$ values $<0.05$ were considered to be significant. Statistical methods used in the analysis were described in figure legends or experimental procedures.

A

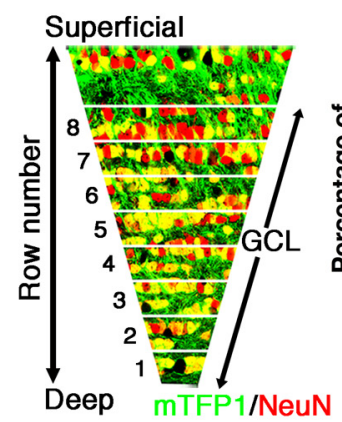

B

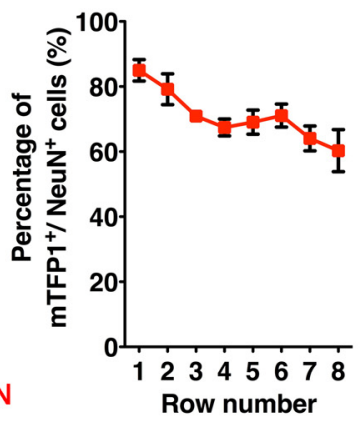

$\mathbf{F}$

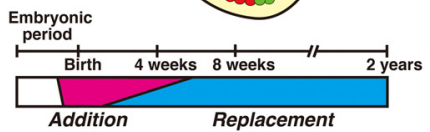

P7

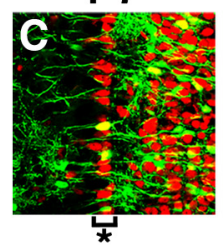

P28

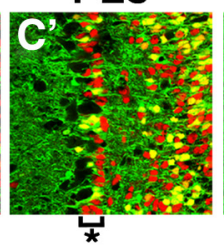

P90

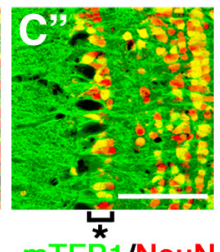

mTFP $1 /$ NeuN
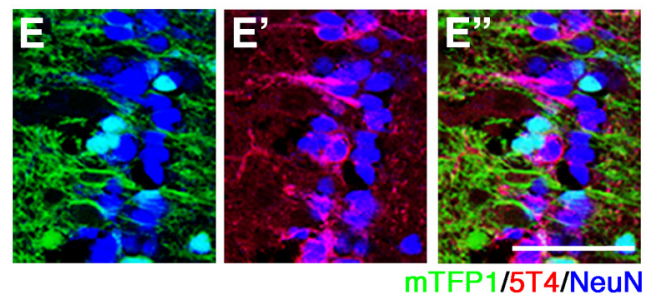

D

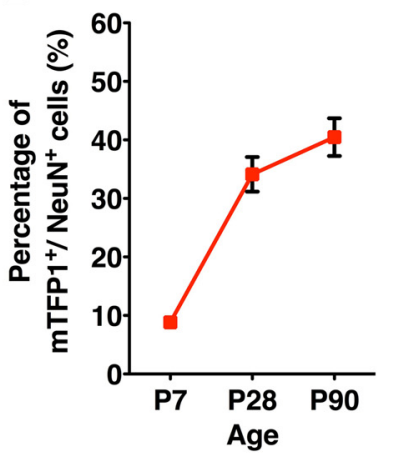

Figure 2. Integration modes of newborn neurons in the $\mathrm{GCL}$ of the postnatal $\mathrm{OB} . A, B$, Coronal sections through the $\mathrm{GCL}$ of the OB from P90 mGFAP-Cre;R26R-CAG-LoxP-mTFP1 mice were divided into eight rows, and the ratios of $m$ TFP1 to NeuN labeling were determined in each row. $C-C^{\prime \prime}{ }^{\prime}$, Outer GCLs of mGFAP-Cre;R26R-CAG-LoXP-mTFP1 mice at P7, P28, and P90 were immunostained by anti-NeuN (red) antibody. Outer GCLs are indicated by asterisks. A restricted number of newborn neurons were incorporated into the outer GCL of the OB. D, Quantification of mTFP1 versus NeuN labeling ratios in outer GCS of the OB during postnatal development. Data points represent mean \pm SD from at least three mice. $\boldsymbol{E}-\boldsymbol{E}^{\prime \prime}$, Outer GCs labeled by $5 \mathrm{~T} 4$ (red) were typically negative for mTFP1 labeling. $\boldsymbol{F}$, Proposed model of integration modes of postnatal-born GCs in the main OB. In the OB schematics, postnatalborn GCs and embryonic-born GCs were indicated by green dots and red dots, respectively. In the $\mathrm{OB}$, newborn neurons are integrated into and build up the basic architecture of the $O B$ neural circuit before 4 weeks of age. After that, it is likely that the dynamic turnover of old GCS and newborn GCs occurs continuously. Postnatal-born GCs are preferentially integrated into deep regions of the $\mathrm{GCL}$ in the $\mathrm{OB}$. Scale bars: $C^{\prime \prime}, 100 \mu \mathrm{m} ; \boldsymbol{E}^{\prime \prime}, 50 \mu \mathrm{m}$.

ifications (Imayoshi et al., 2008). Mice were food-restricted to maintain $80-85 \%$ of their free feeding weights and trained to associate one of the enantiomers of Carvone with sugar reward for $4 \mathrm{~d}$. During the training, the mice received four 10 min trials a day: two trials for an odor paired with sugar reward and two for the unpaired odor. In the test session, each test odorant $(20 \mu \mathrm{l}$ soaked into a $2 \mathrm{~cm} \times 2 \mathrm{~cm}$ filter paper) was placed independently, without sugar, in a cage $(26 \times 40 \times 18 \mathrm{~cm})$ under the bedding ( $5 \mathrm{~cm}$ depth). On days $1-4$, the sugar reward was associated with

\section{Results}

The mode of integration of postnatalborn neurons into the $\mathrm{OB}$

To investigate how and to what extent newborn, postnatal neurons contribute to functional $\mathrm{OB}$ neural circuit formation, we used Cre/LoxP-based genetic labeling to visualize nearly all newborn neurons with fluorescent proteins and analyzed OB development during the postnatal period. In $m G F A P$-Cre transgenic mouse, Cre expression is regulated by a $15 \mathrm{~kb}$ mouse GFAP mini-gene and begins in postnatal NSCs but not in embryonic NSCs (Garcia et al., 2004). We crossed mGFAP-Cre mice with R26R-CAG-LoxP$m T F P 1$ reporter mice (Imayoshi et al., 2012), which can induce permanent irreversible Cre-mediated recombination in postnatal NSCs and followed the subsequent integration of mTFP1-labeled newborn neurons in the $\mathrm{OB}$ (Fig. $1 A-H$; Table 1). To confirm that leaky Cre-mediated recombination during embryonic development and in preexisting neurons does not occur in $m G F A P-C r e ; R 26 R-C A G-$ LoxP-mTFP1 double Tg mice, we labeled embryonically born GCs by administering BrdU to these mice at E15.5, and analyzed the OBs at postnatal day 60 (P60) (Fig. $1 C$ ). Only $1.23 \pm 0.71 \%$ of BrdUpositive embryonically born GCs displayed mTFP1 expression in $M G F A P-C r e$; R26R-CAG-LoxP-mTFP1 mice (Fig. 1D), indicating that $\mathrm{MTFP} 1$ labeling was specifically induced in postnatal-born GCs and excluded from embryonically born GCs. In quite small subsets of mTFP1-positive postnatal-born GCs, BrdU signal was observed, but signal intensity in these cells was always very weak, suggesting that these double-labeled GCs were derived from NSCs retaining BrdU because of the limited number of cell divisions between E15.5 and P60. From these results, we concluded that mTFP1-reporter labeling is restricted to postnatal-born neurons in our Tg model.

In $m G F A P-C r e ; R 26 R-C A G-L o x P-m T F P 1$ mice, large numbers of migrating, mTFP1-positive neuroblasts were observed in the RMS and core region of the OB at P7 (Fig. $1 E-E^{\prime \prime \prime}$ ). Subsets of mTFP1-positive newborn neurons already migrated to the GCL 
at P7 and expressed the mature GC marker NeuN (Mullen et al., 1992) (Fig. $\left.1 E-E^{\prime \prime \prime}\right)$. In the $\mathrm{OB}$ of $\mathrm{P} 7$ pups, large numbers of mTFP1-negative GCs were observed. These mTFP1-negative GCs were likely generated during the embryonic period. NSCs existing in the lateral ganglionic eminence give rise to $\mathrm{OB}$ interneurons during embryonic development (Stenman et al., 2003; Long et al., 2007; Batista-Brito et al., 2008). Cell counting of GCs in the OB during postnatal development demonstrated that a considerable proportion of GCs, corresponding to $\sim 25 \%$ of the adult OB GCs, were already generated before P7 (Fig. 1I$K)$. By P28, greater numbers of mTFP1positive GCs were observed throughout the OB (Fig. $1 F-F^{\prime \prime \prime}$ ), comprising $\sim 60 \%$ of GCs (Fig. $1 H$ ). By P90, 80\% of the OB GCs were labeled by mTFP1 (Fig. $1 G, H$; Table 1). These results indicate that most of the OB GCs are generated during the postnatal period, as previously estimated by $\left[{ }^{3} \mathrm{H}\right]$-thymidine- and BrdU-labeling methods (Rosselli-Austin and Altman, 1979; Bayer, 1983; Lemasson et al., 2005).

It has been shown that there are significant regional differences in the properties of NSCs along dorsoventral/rostrocaudal axes of the postnatal SVZ of the LV (Kriegstein and Alvarez-Buylla, 2009; Ihrie and Alvarez-Buylla, 2011). To exclude the possibility that $m G F A P$-Cre targets a biased population of the stem cell pool, we also used the Nestin-CreER ${ }^{T 2}$ transgenic mouse, in which tamoxifen-inducible $\mathrm{CreER}^{\mathrm{T} 2}$ proteins are specifically expressed by NSCs throughout development and in the adult brain. Tamoxifen administration to pups induces very efficient recombination in postnatal NSCs without recombination during embryogenesis (Imayoshi et al., 2010; and data not shown). We injected tamoxifen to P1 pups of Nestin-CreER ${ }^{T 2} ; R 26 R-L o x P$ $E C F P$ double transgenic mice, inducing permanent, irreversible Cre-mediated recombination in postnatal NSCs, and followed the subsequent integration of ECFP-labeled newborn neurons in the OB (Table 2). Consistent with our results when using the $m G F A P$-Cre driver, gradual increase of Cre-reporter expressing GCs was observed in the postnatal OB, and the proportions of labeled GCs were quite similar between the two Tg models (Table 1).

Considering that our cell counting of total GCs in the OB shows no further increase in the number of GCs after P35 (Imayoshi et al., 2008) (Fig. $1 K$ ), the substantial increase in mTFP1-labeled newborn neurons between P28 and P90 raised the possibility that the integration of the newly generated neubars, $100 \mu \mathrm{m}$.
OB PGL
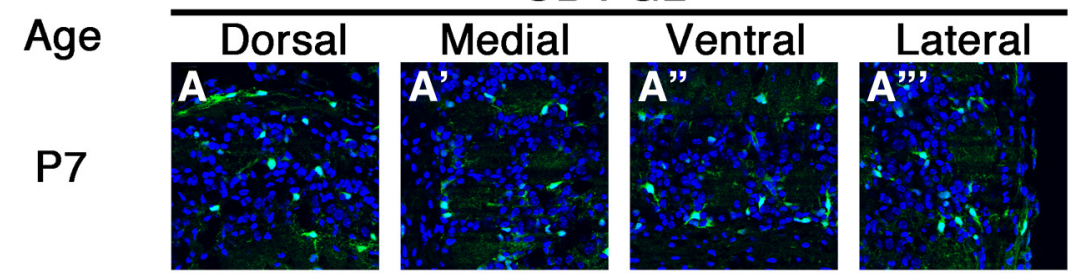

1 month
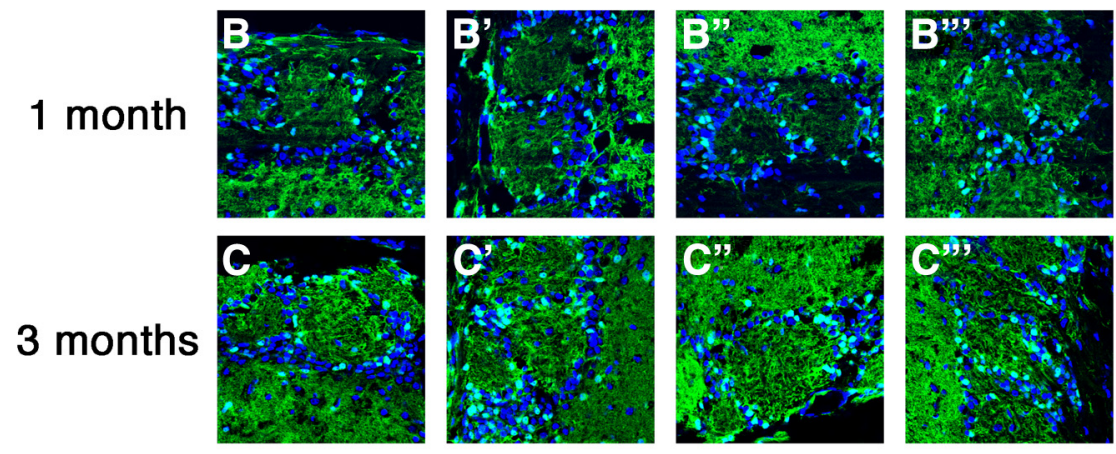

12 months
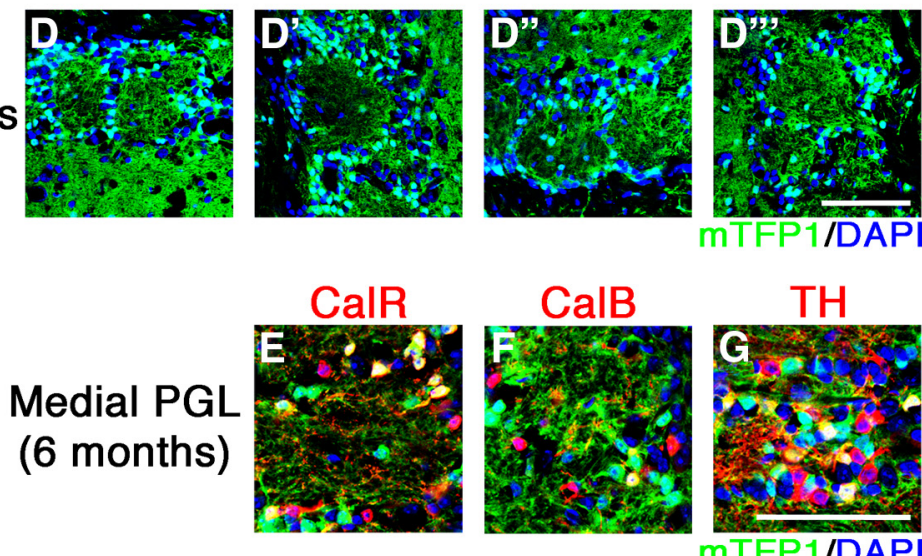

H

|
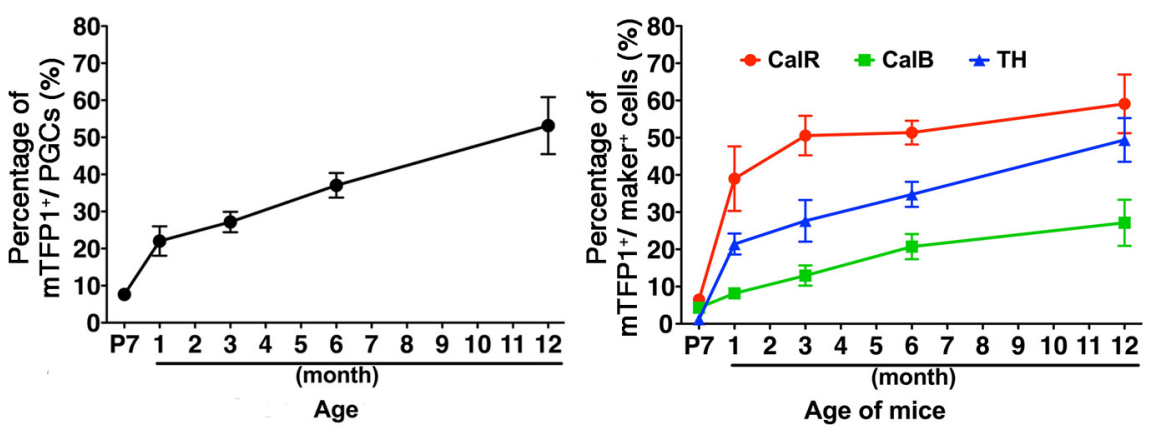

Figure 3. Postnatal development of the PGL in the OB. $\boldsymbol{A}-\boldsymbol{D}^{\prime \prime \prime}{ }^{\prime \prime}$, The PGL of mGFAP-Cre;R26R-CAG-LoxP-mTFP1 mice at P7 $\left(\boldsymbol{A}-\boldsymbol{A}^{\prime \prime \prime}\right)$, 1 month $\left(\boldsymbol{B}-\boldsymbol{B}^{\prime \prime \prime}\right)$, 3 months $\left(\boldsymbol{C}-\boldsymbol{C}^{\prime \prime \prime}\right)$, and 12 months $\left(\boldsymbol{D}-\boldsymbol{D}^{\prime \prime \prime}\right)$ of age. Postnatal-born PGCs were visualized via mTFP1 fluorescence (green). The number of $\mathrm{mTFP1}$-expressing PGCs increased during the postnatal periods. $\boldsymbol{E}-\boldsymbol{G}$, Representative images of immunostaining by CalR ( $\boldsymbol{E}$; red), CalB ( $\boldsymbol{F}$; red), or TH ( $\boldsymbol{G}$; red) in the medial PGL at 6 months of age. $\boldsymbol{H}$, Proportions of mTFP1expressing cells in the PGLs of the OB during postnatal development. I, Proportions of mTFP1-labeling in the CaIR-, CalB-, and TH-expressing PGCs during postnatal development. Data points represent mean \pm SD from at least three mice. Scale

rons changes from an addition to replacement mode during this period. We propose that $\sim 25 \%$ of GCs are generated from embryonic NSCs and that newborn neurons derived from postnatal NSCs are integrated into the $\mathrm{OB}$ neural circuit by an addition mode, and contribute to the increase in the total GC number until P35. After P35, because the total number of GCs does not 
A
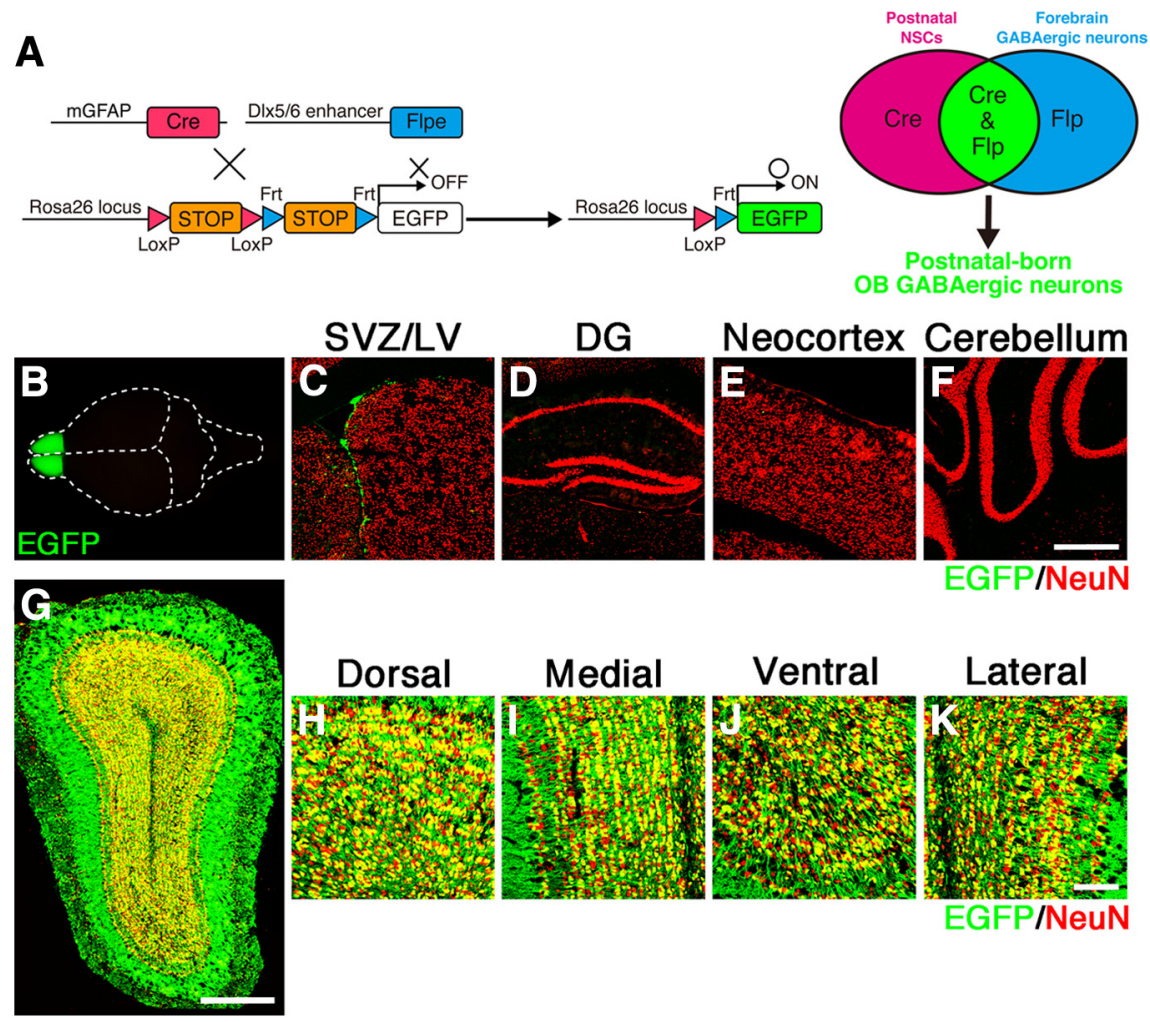

Figure 4. Specific genetic targeting of postnatal-born GCS by Cre/loxP- and Flp/Frt-mediated intersectional strategy. $A$, Schematic drawing of genetic strategy to selectively target postnatal-born GABAergic neurons by mGFAP-Cre and D/x5/6-Flpe transgenic mouse strains. $\boldsymbol{B}$, Dorsal view of the whole brain from adult mGFAP-Cre;D/x5/6-Flpe;R26R-CAG-LoxP-Frt-EGFP triple transgenic mice. $(-\boldsymbol{K}$, EGFP expressions (green) were specifically expressed by neuroblasts in the SVZ of the LV $(\boldsymbol{C})$ and by the GABAergic interneurons in the $\mathrm{OB}(\boldsymbol{G}-\boldsymbol{K})$, but not in the $\mathrm{DG}(\boldsymbol{D})$, neocortex $(\boldsymbol{E})$, or cerebellum $(\boldsymbol{F})$. Scale bars, $500 \mu \mathrm{m}(\boldsymbol{F}, \boldsymbol{G})$ and 100 $\mu \mathrm{m}(\boldsymbol{K})$.

significantly change (Fig. $1 K$ ), newly generated neurons must be proportionately replacing preexisting GCs. Therefore, newborn neurons are integrated into and build up the basic architecture of the $\mathrm{OB}$ neural circuit before P35. After P35, it is likely that the dynamic turnover of old GCs and recently generated, new GCs occurs continuously, contributing to plasticity in the $\mathrm{OB}$ neuronal network (Fig. 2F).

Heterogeneous integration of postnatal-born GCs in the OB We then asked whether newborn neurons are uniformly integrated into the GCL of the $\mathrm{OB}$ or whether there exist unique rules for the integration of newborn neurons. Coronal sections of the GCL were divided into eight rows from deep to superficial regions (Fig. 2A), and we determined the proportions of mTFP1labeled GCs along the entire deep to superficial axis of the GCL of P90 mice. In the deep region, nearly 90\% of GCs displayed mTFP1 expression; whereas in the superficial region, only $60 \%$ of GCs were labeled by mTFP1, indicating limited integration of postnatal-born GCs in the superficial area of the GCL of the OB (Fig. 2A,B). Thus, newborn neurons generated from postnatal NSCs are preferentially integrated into the inner region of the GCL; and in the superficial area, embryonic NSC-derived GCs comprise approximately half of all GCs and are maintained without replacement (Fig. $2 F$ ).

In the mitral cell layer of the OB, outer GCs become aligned along the mitral cell bodies (Fig. $2 C-C^{\prime \prime}$, asterisks). We separately analyzed the mTFP1 labeling ratio in these outer GCs in $m G F A P$ Cre;R26R-CAG-LoxP-mTFP1 double transgenic mice (Fig. $2 C, D)$. At P28, only $\sim 35 \%$ of outer GCs expressed mTFP1; and at

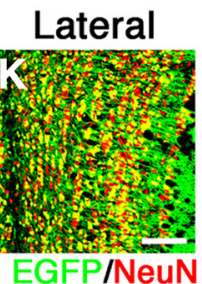

P90, 40\%. It was reported that the 5T4 glycoprotein is specifically expressed in outer GCs and regulates dendritic arborization (Imamura et al., 2006; Yoshihara et al., 2012). Figure $2 E-E^{\prime \prime}$ shows that 5T4-expressing outer GCs were typically negative for mTFP1-labeling, indicating that approximately half of the outer GCs and GCs in the superficial GCL are generated during the embryonic period and are stably maintained for an extended period. This limited integration of labeled newborn neurons in the superficial GCLs was similarly observed in P1-tamoxifentreated Nestin-CreER ${ }^{T 2}$;R26R-LoxP-ECFP mice (data not shown). Thus, we conclude that postnatal-born GCs are preferentially integrated into deep regions of the $\mathrm{OB}$, whereas embryonically derived GCs are maintained in the outer/superficial areas without replacement (Fig. 2F).

\section{Postnatal neurogenesis of PGCs in the $\mathrm{OB}$}

Newly generated neurons in the postnatal brain also differentiate into PGCs in the PGL as well as GCs in the OB (Lledo et al., 2006; Kohwi et al., 2007). We analyzed integration of labeled newborn neurons in the PGL of $m G F A P-C r e ; R 26 R-C A G-$ LoxP-mTFP1 double transgenic mice (Fig. 3). Because some major cell types appear devoid of immunoreactivity for NeuN in the PGL (Bagley et al., 2007), we quantified mTFP1-labeling ratios among DAPI-stained PGCs. PGCs were progressively labeled with mTFP1 during postnatal development and in the adult brain (Fig. $3 A-D, H$ ). The proportion of labeled PGCs in the $\mathrm{OB}$ was $\sim 5 \%$ at $\mathrm{P} 7$ and increased to $\sim 25 \%$ at 3 months of age, indicating that postnatal-born neurons contribute to formation and modification in the neural circuit of the PGL. PGCs are subdivided into at least three subtypes based on immunoreactivity to calretinin (CalR), calbindin-28K (CalB), and $\mathrm{TH}$, which show different turnover rates (Kosaka et al., 1998; Kohwi et al., 2007; Ninkovic et al., 2007). In mice, all three PGC subtypes seem to be GABA-expressing inhibitory neurons, but the physiological characteristics and functional roles of each neuronal subtype have not been well determined. We also estimated the proportion of labeled postnatal-born neurons among these three PGC subtypes (Fig. $3 E-G, I$ ). A progressive increase of mTFP1-labeling was observed in all three PGC subtypes, but the labeling ratio was the highest in CalR-expressing and lowest in CalB-expressing PGCs, indicating that each PGC subtype has the unique replacement and/or addition mode. Therefore, as reported previously (Kohwi et al., 2007; Ninkovic et al., 2007), all major subtypes of periglomerular OB interneurons are continuously generated from the postnatal period throughout adulthood, but these cells mature and are replaced at different rates. It was reported that $\mathrm{TH}$-positive PGCs are integrated to PGLs as an addition manner (Adam and Mizrahi, 2011; Sawada et al., 2011). These results suggest that continuous postnatal neurogenesis dynamically contributes to formation and reorganization of the neural circuit in the glomerulus, consisting of terminals of 
the olfactory nerve and the dendrites of mitral, periglomerular, and tufted cells.

Together, our comprehensive analysis using the Cre/LoxP-based genetic labeling method revealed the lifetime integration dynamics of interneurons born during postnatal OB development. Previous estimations of postnatal development of the OB inhibitory network were based on lineage-tracing experiments of limited populations using $\left[{ }^{3} \mathrm{H}\right]$-thymidine- and BrdU-labeling methods (Rosselli-Austin and Altman, 1979; Bayer, 1983; Lemasson et al., 2005). Our genetic labeling study targeting nearly all newborn neurons with fluorescent proteins provided the direct evidence of integration modes of postnatalborn $\mathrm{OB}$ interneurons. Although similar Cre/LoxP-based genetic labeling methods were applied for newly generated OB interneurons, most studies focused on adultborn neurons (Ahn and Joyner, 2005; Lagace et al., 2007; Ninkovic et al., 2007; Imayoshi et al., 2008). Our fate-mapping study during postnatal OB development, combined with cell counting of total GCs, revealed that, from the age of 1 month onward, the integration of newborn GCs in the $\mathrm{OB}$ switches from addition to replacement mode. Interestingly, this replacement is largely restricted to the deep layers and does not extend to the superficial layers. Embryonically derived GCs are located mainly in the superficial layers, and there is limited turnover of this population (Fig. 2F).

\section{Specific genetic targeting of postnatal-}

\section{born GCs in the OB}

The OB is the first relay station of the central olfactory system in the mammalian brain. Synaptic connections in the external plexiform layer (EPL) of the $\mathrm{OB}$ are dominated by dendrodendritic reciprocal synapses between lateral dendrites of mitral/tufted cells and GCs, the latter being most numerous type of inhibitory interneurons in the OB (Isaacson and Strowbridge, 1998; Shepherd and Greer, 2004; Egger and Urban, 2006). The GC-to-mitral/tufted dendrodendritic inhibition plays pivotal roles in odor representation and processing (Yokoi et al., 1995; Shepherd and Greer, 2004). PGCs, which synapse within and between glomeruli, also mediate lateral inhibition in the $\mathrm{OB}$ together with granule cells. They have inhibitory synapses on mitral cells and tufted cells (Shepherd and Greer, 2004).

By using inducible genetic labeling strategies, we demonstrated above that the prolonged supply of newborn neurons from the SVZ/LV contributes to the formation of neuronal circuits in the postnatal OB. To investigate whether the postnatal

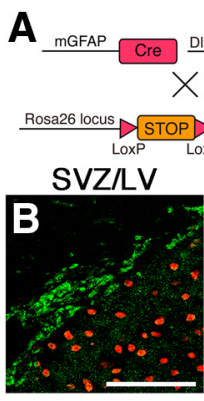

E

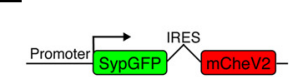

\section{G}

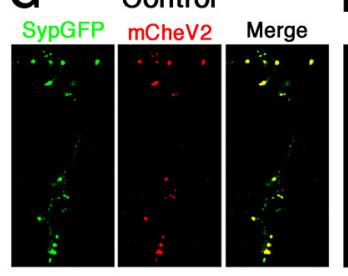

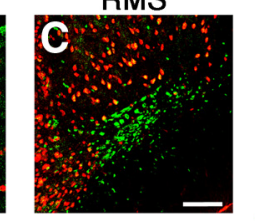

$\mathbf{F}$

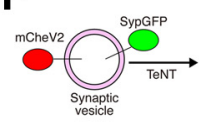

H OB-mutant

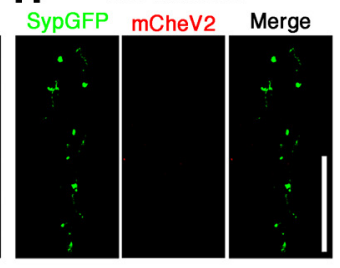

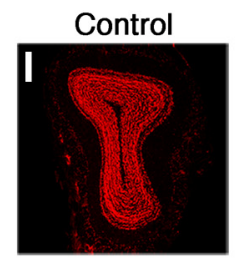
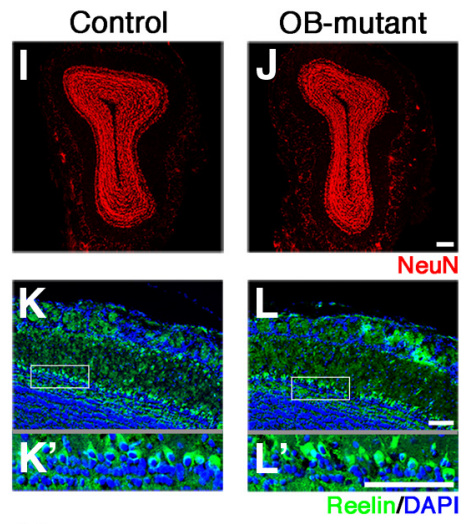

M

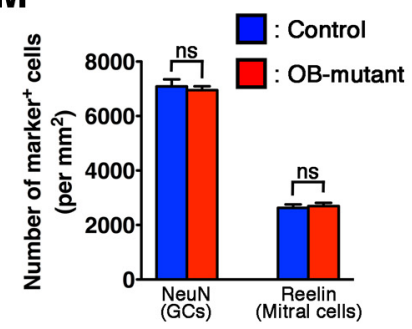

Figure 5. Inhibiting synaptic transmission in postnatal-born $\mathrm{GCS}$ in the $\mathrm{OB}$. $\boldsymbol{A}$, Schematic drawing of specific silencing of postnatal-born $0 B$ neurons using R26R-CAG-LoxP-Frt-EGFP-TeNT transgenic mouse strain. $\boldsymbol{B}-\boldsymbol{D}$, EGFP-TeNT expression was specifically observed in the SVZ/LV (B), RMS (C), and OB (D) of adult mGFAP-Cre;Dlx5/6-Flpe;R26R-CAG-LoxP-Frt-EGFP-TeNT triple transgenic mice. $\boldsymbol{E}$, A schematic drawing of Moloney viral vector encoding bicistronic GFP-fused synaptophysin (SypGFP) and mCherry-fused VAMP2 (mCheV2). Virus was injected into the SVZ/LV, and the OB was analyzed 4 weeks later. $\boldsymbol{F}, A$ schematic drawing of SypGFP- and mCheV2-labeled synaptic vesicles. TeNT cleaves the $m C h e V 2$, leading to loss of mCheV2 immunoreactivity. $\mathbf{G}, \boldsymbol{H}$, Presence of $\mathrm{mCheV2-positive} \mathrm{puncta} \mathrm{in} \mathrm{OB} \mathrm{sections} \mathrm{from} \mathrm{control} \mathrm{(mGFAP-Cre;R26R-CAG-LoxP-Frt-TeNT} \mathrm{double} \mathrm{transgenic)}$ mice ( $\boldsymbol{G}$ ) and its absence in the sections from OB-mutant (mGFAP-Cre;Dlx5/6-Flpe;R26R-CAG-LoxP-Frt-EGFP-TeNT triple transgenic) mice, indicating specific inhibition of synaptic transmission in postnatal-born $\mathrm{GCS}(\boldsymbol{H})$. $\boldsymbol{I}, \boldsymbol{J}$, Coronal sections of the adult $0 B$ from control and OB-mutant mice stained with anti-NeuN antibodies (red). No apparent histological differences were observed between control and OB-mutant mice. $\boldsymbol{K}-\boldsymbol{L}^{\prime}$, Mitral cells identified by Reelin expression (green) were normally developed in OB-mutant mice. $\boldsymbol{K}, \boldsymbol{L}$, Boxed regions are magnified in $\boldsymbol{K}^{\prime}$ and $\boldsymbol{L}^{\prime}$, respectively. $\boldsymbol{M}$, Graph showing no difference in density of NeuN-positive GCs and Reelin-positive mitral cells in control and OB-mutant mice. The average of three independent samples with SD. ns, Not significant (two-tailed Student's t test). Scale bars, $100 \mu \mathrm{m}\left(\mathrm{B}, \mathrm{C}, \mathrm{K}-\mathrm{L}^{\prime}\right) ; 75 \mu \mathrm{m}(\mathrm{D}) ; 67.5 \mathrm{um}(\mathrm{G}, \mathrm{H}) ; 200 \mu \mathrm{m}(\mathrm{I}, \mathrm{J})$.
A

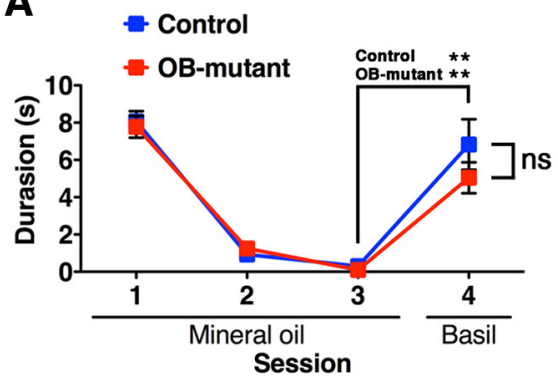

B

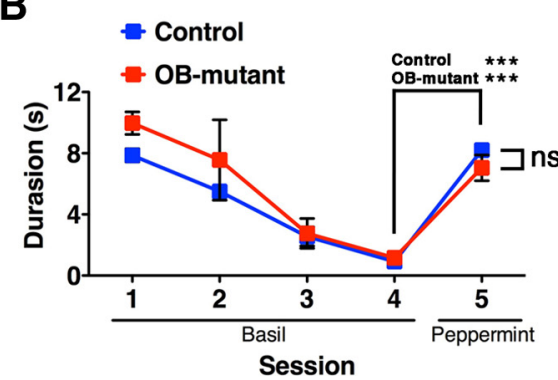

Figure 6. Habituation-dishabituation tests. $\boldsymbol{A}$, Mean investigation time (seconds) \pm SEM in the habituation (trials 1-3) and dishabituation trials. In trials 1-3, filter papers with mineral oil were presented to mice for 3 min with 10 min intervals. In trial 4, filter papers scented with basil were presented to the mice for $3 \mathrm{~min}$. There were no differences in investigation time in each trial for the control $(n=6)$ and OB-mutant $(n=6)$ mice. Both groups showed significantly increased investigation after the dishabituating odor (between trials 3 and 4). B, Habituation (trials 1-4; basil odor) and dishabituation trials (trials 5; peppermint odor). Both groups again showed significantly increased investigation after the dishabituating odor (between trials 4 and 5). ns, Not significant. ${ }^{* *} p<0.01$ (two-tailed Student's $t$ test). ${ }^{* * *} p<0.001$ (two-tailed Student's $t$ test). neurogenesis functionally contributes to olfactory-related behaviors, we performed a loss-of-function study of postnatal-born OB interneurons. In order that the study of the cellular, network, and behavioral consequences of this manipulation is not confounded, it is vital that our manipulation does not impact other neurogenic 


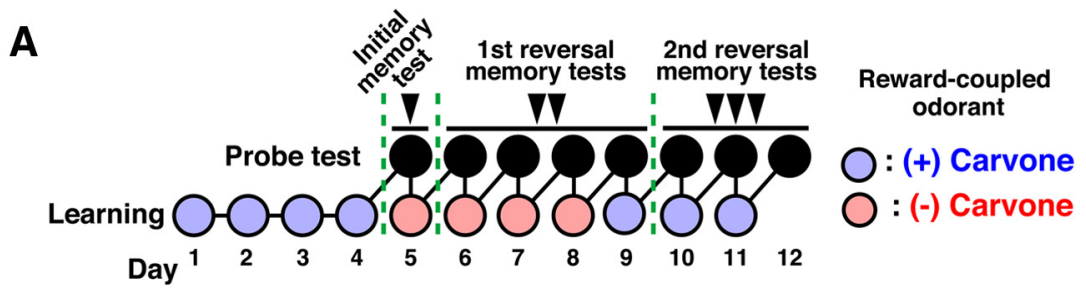

B

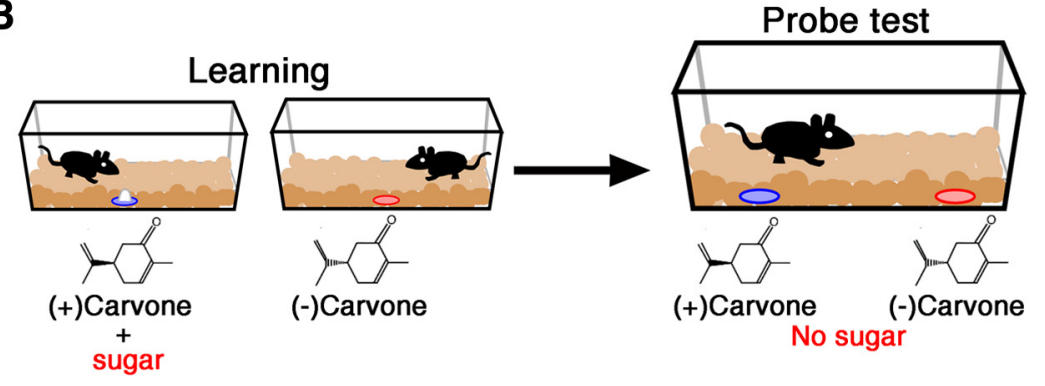

C
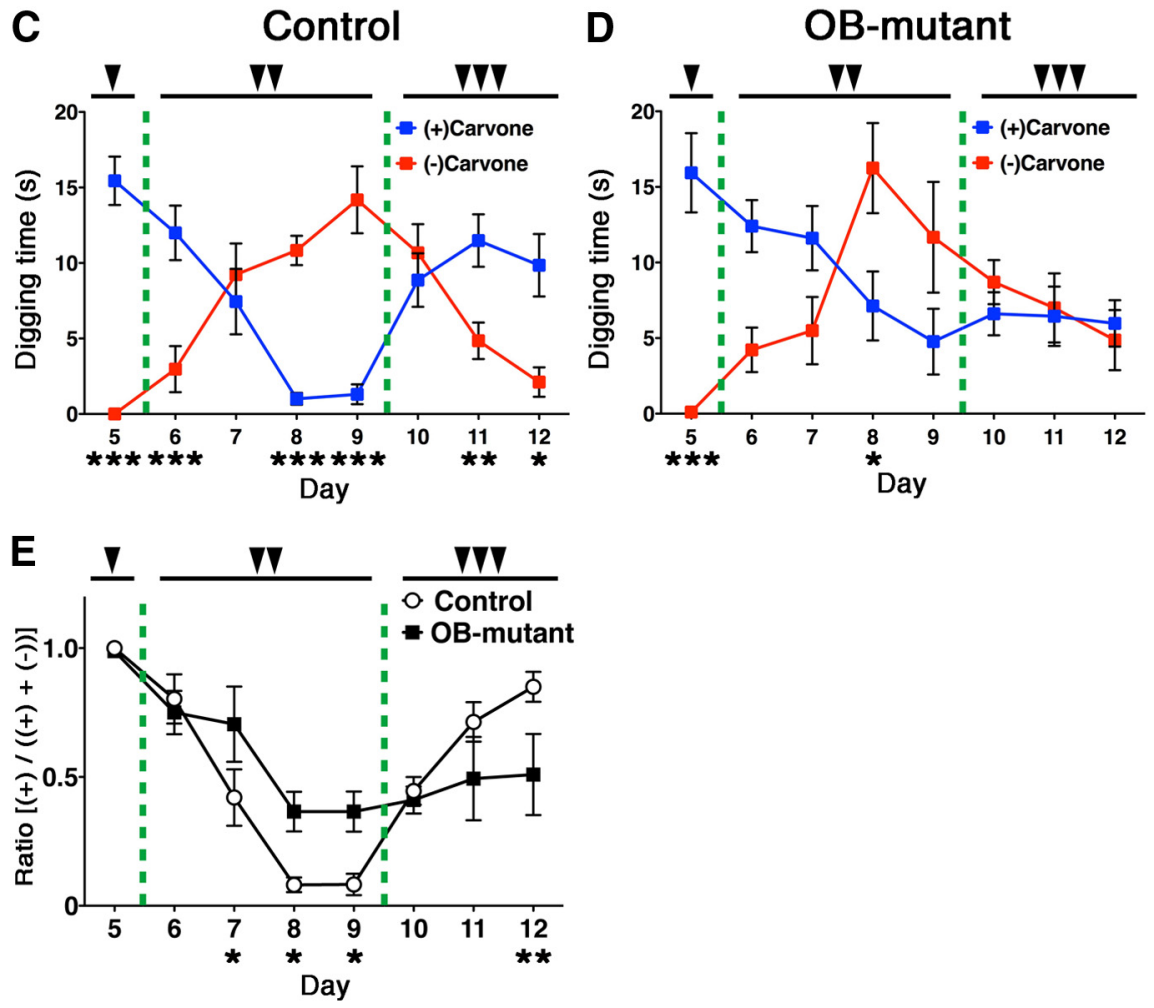

Figure 7. Postnatal-born GCs regulate flexible olfactory associative learning. $A, B, A$ schematic drawing of the experimental time course $(\boldsymbol{A})$, and schematic representation of the olfactory associative memory test $(\boldsymbol{B})$. Three-month-old control and $O B$ mutant mice were trained for $4 \mathrm{~d}$ to associate a reward (sugar grains) with either of two related odorants $((+)$ - and $(-)$-carvone enantiomers). On day 5 (single arrowhead), the carvone enantiomers were presented without the sugar reward, and digging time was measured for each pair of related odorants. After the initial probe test, the sugar reward was associated with the other odorant, and the first reversal learning task was started on the same day. From days 6 to 9 (double arrowheads), probe tests for reversal learning were performed every day, and reversal learning trials were conducted immediately after each probe test. 0n day 9 , after the probe test, the sugar reward was again associated with the initial odorant, and the second reversal learning was started. From days 10 to 12 (triple arrowheads), probe tests for the second reversal learning were performed every day followed by continuing learning. $\boldsymbol{C}, \boldsymbol{D}$, Control $(n=6)$ and $\mathrm{OB}$-mutant $(n=6)$ were subjected to the above flexible olfactory associative memory test. Mean digging times (seconds) \pm SEM during the 4 min probe test period are shown. ${ }^{*} p<0.05 ;{ }^{* *} p<0.01 ;{ }^{* * *} p<0.001$; two-way repeated-measures ANOVA of odor and day followed by Fisher's LSD post hoc test (control; odor: $F_{(1,5)}=4.542, p=$ 0.0863; day: $F_{(7,35)}=1.386, p=0.2420$; interaction: $F_{(7,35)}=20.18, p<0.0001,0 \mathrm{~B}$-mutant: odor: $F_{(1,5)}=1.556, p=0.2803$; day: $F_{(7,35)}=1.731, p=0.1423$; interaction: $\left.F_{(7,35)}=7.471, p<0.0001\right) . \boldsymbol{E}$, Ratio was calculated for probe test period using the digging times according to the following formula: $(+)$-carvone/ $(+)$-carvone $+(-)$-carvone). ${ }^{*} p<0.05 ;{ }^{* *} p<0.01$; twoway repeated-measures ANOVA of mouse group and day followed by Fisher's LSD post hoc test (group: $F_{(1,10)}=0.2566, p=$ 0.6247; day: $F_{(7,70)}=19.31, p<0.0001$; interaction: $\left.F_{(7,70)}=3.957, p<0.0012\right)$. domains, including the hippocampal DG during the postnatal stages. To this end, we adapted a more sophisticated intersectional genetic strategy based on dual recombination using both the Cre and Flp recombinases (Branda and Dymecki, 2004; Imayoshi et al., 2011). In Cre- and Flpdual recombinase-responsive alleles, the reporter/effector-encoding sequence is interrupted by a loxP-flanked STOP cassette, followed by an Frt-flanked STOP cassette. Using this strategy, the reporter/ effector proteins are expressed only when Cre and Flp are at least at some point coincidently or sequentially present within the target population (Fig. 4A). We used Dlx5/6-Flpe transgenic mice as the Flpdriver strain, which induces efficient recombination specifically in forebrain GABAergic interneurons, including the OB interneurons (Miyoshi et al., 2010; Imayoshi et al., 2012). Newborn neurons in the hippocampal DG are glutamatergic excitatory neurons and hence not in the Dlx5/6-lineage. Indeed, when we crossed mGFAP-Cre and Dlx5/6-Flpe mice with R26R-CAG-LoxP-Frt-EGFP (original strain name is RCE:dual) mice (Miyoshi et al., 2010), EGFP reporter expression was specifically observed by neuroblasts in the SVZ/LV and RMS and by interneurons in the OB (Fig. 4B, $C, G-K$ ), and not in newborn neurons in the DG (Fig. 4D), cortical astrocytes (Fig. 4E), or Bergmann glial cells of the cerebellum (Fig. 4F). Although we had an extra step of recombination involving Flpe- and Frt-flanked STOP cassette in the triple transgenic line, the efficiency of labeling in the OB was comparable with that found in the original labeling just by Cre ( $M G F A P-C r e ; R 26 R$ CAG-LoxP-mTFP1) (Figs. 1 and $4 G-K$ ), and EGFP expression was specifically limited to the postnatal-born inhibitory neurons in the OB. Newborn glutamatergic OB interneurons should not be targeted because the Dlx5/6-Flpe transgenic line induces specific recombination in GABAergic interneurons (Miyoshi et al., 2010).

To specifically inhibit the function of postnatal-born $\mathrm{OB}$ interneurons, we used the R26R-CAG-LoxP-Frt-EGFPTeNT mouse strain (Fig. 5A). TeNT (tetanus toxin light chain) suppresses vesiclemediated neurotransmitter release by cleaving the synaptic-vesicle-associated membrane protein VAMP2. In $m G F A P$ Cre;Dlx5/6-Flpe;R26R-CAG-LoxP-FrtEGFP-TeNT triple transgenic (designated as OB-mutant) mice, EGFP-TeNT expression was observed in neuroblasts in the SVZ/LV, RMS, and in GCs in the OB (Fig. $5 B-D$ ). To examine whether synap- 
tic transmissions within postnatal-born GCs are inhibited, a genetically engineered Moloney viral vector was injected into the SVZ/LV (Nakashiba et al., 2012) (Fig. 5E-H). Four weeks after the viral injection, mCherry-fused VAMP2-positive puncta (mCheV2) were observed in the $\mathrm{OB}$ of control mice. These puncta were superimposed nearly perfectly with GFPfused synaptophysin (SypGFP). Conversely, in OB-mutant mice, mCheV2 signal was not observed in SypGFP-positive puncta, suggesting that synaptic transmission of postnatal-born GCs is inhibited (Fig. 5G,H). Basic histological structures of the OBs, including numbers of GCs and Reelin-expressing mitral cells, of control and OB-mutant mice were indistinguishable (Fig. 5I-M).

\section{Postnatal-born $\mathrm{OB}$ interneurons are essential for flexible olfactory associative learning}

To examine whether the prolonged postnatal neurogenesis is required for the behavior of animals (i.e., in discrimination and memory of odors), we performed a habituation-dishabituation test in control and OB-mutant mice. Spontaneous odor exploration in OB-mutant mice was not different from that of controls (Fig. 6A). Although it is quite difficult to experimentally prove that odor detection is completely preserved, results of the habituation-dishabituation test indicate that $\mathrm{OB}$-mutant mice can detect and respond to odor stimuli as well as control mice (Fig. 6B).

To investigate the influence of inhibition of postnatal $\mathrm{OB}$ neurogenesis on odor-associated learning and memory, 3-month-old control and OB-mutant mice were trained for $4 \mathrm{~d}$ to associate one of two related odorants (enantiomers) with a sugar reward (Fig. $7 A, B$ ). On day 5 , we separately placed both odors without sugar beneath the cage bedding and measured the digging time spent near each odor. Both control and OB-mutant mice spent significantly more time near the odorants associated with sugar rewards (Fig. $7 C-E$ ), indicating that both were able to acquire olfactory associative memory. It was reported that such simple olfactory associative learning was not affected in adult mice, in which newly generated neurons were eliminated by DT-A (Imayoshi et al., 2008; Sakamoto et al., 2011). Therefore, in the absence of postnatal-born OB interneurons, simple discrimination of two related odorants and acquisition of odor-associated memory are not fundamentally affected, although more difficult tasks of odor-associated memory may depend on postnatal neurogenesis (Alonso et al., 2012).

Thus, we conducted reversal-learning experiments using the same olfactory associative learning test. After the initial odor-

B
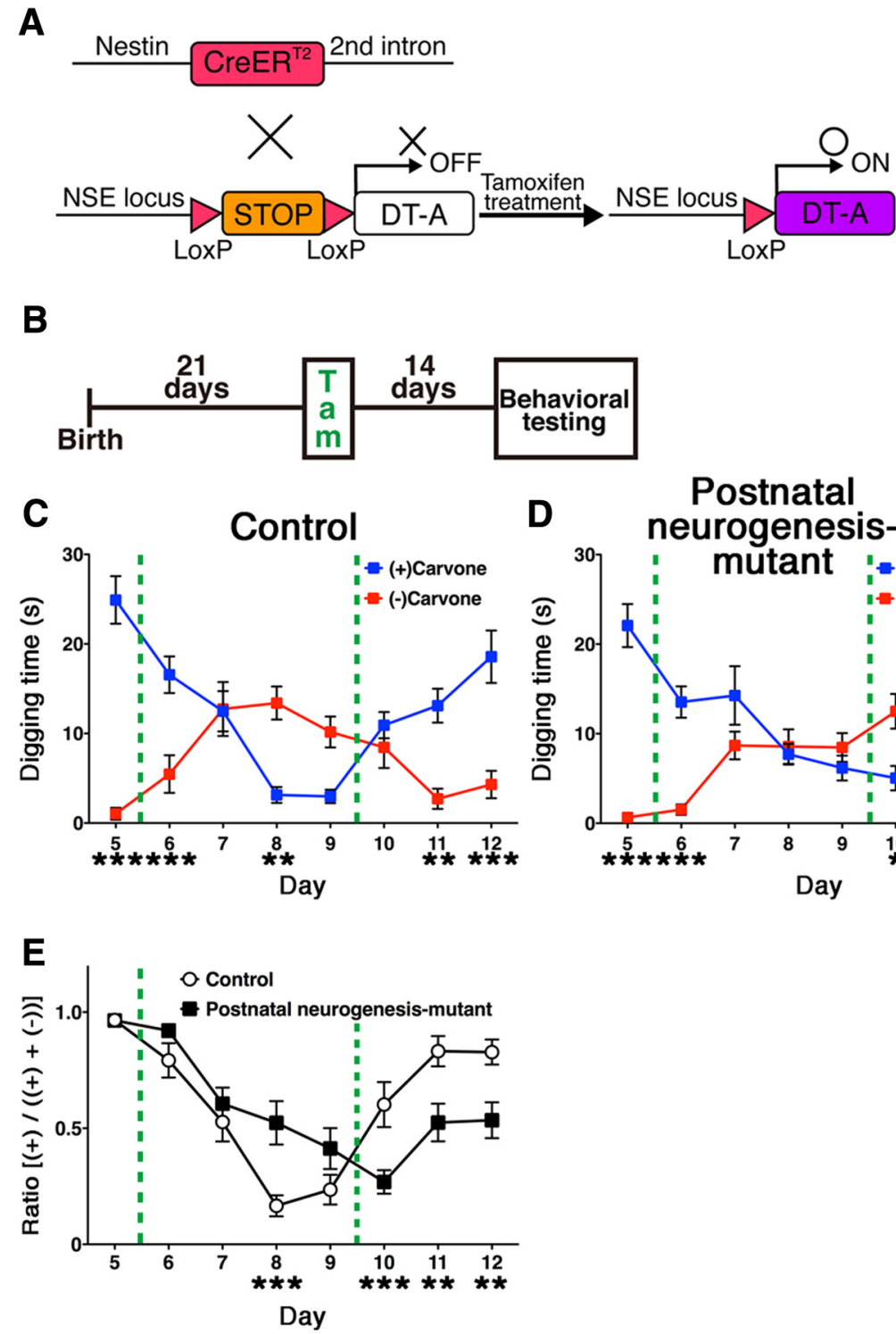

Figure 8. Late-postnatal neurogenesis is required for flexible olfactory associative learning. $\boldsymbol{A}$, Schematic drawing of specific ablation of newly generated neurons. Tamoxifen-inducible Nestin-CreER ${ }^{T 2}$ mice were crossed with NSE-LoxP-DTA mice, in which the LoxP-Stop-LoxP-IRES-DT-A gene cassette was knocked into the 3 ' -noncoding region of the NSE gene. After tamoxifen administration in adult mice, CreER ${ }^{\mathrm{T2}}$ is activated and DT-A is ready for expression. In newly generated neurons, the NSE promoter becomes active and induces apoptotic cell death by the expression of DT-A. B, Tamoxifen or oil vehicle was administered to P21 transgenic mice. At $14 \mathrm{~d}$ after treatment, control $(n=9)$ and neurogenesis-mutant $(n=9)$ mice were subjected to the olfactory associative memory tests described in Figure 7A, B. C, D, Postnatal neurogenesis-mutant mice showed severe impairment of flexible associative olfactory learning and memory. Mean digging times (seconds) \pm SEM during the 4 min probe test period are shown. ${ }^{*} p<0.05 ;{ }^{* *} p<0.01$; ${ }^{* * *} p<0.001$ : two-way repeated-measures ANOVA of odor and day followed by Fisher's LSD post hoc test (control; odor: $F_{(1,8)}=22.22$, $p=0.0015$; day: $F_{(7,56)}=3.229, p=0.0052$; interaction: $F_{(7,56)}=18.12, p<0.0001$, postnatal neurogenesis-mutant: odor: $F_{(1,8)}=$ $27.36, p=0.0008$; day: $F_{(7,56)}=2.352, p=0.0353$; interaction: $\left.F_{(7,56)}=12.42, p<0.0001\right)$. $\boldsymbol{E}$, Ratio was calculated for probetest period using the digging times according to the following formula: $(+)$-carvone/( + -carvone $+(-)$-carvone). ${ }^{* *} p<0.01 ;{ }^{* * *} p<0.001$; two-way repeated-measures ANOVA of mouse group and day followed by Fisher's LSD post hoc test (group: $F_{(1,16)}=0.4255, p=0.5235$; day: $F_{(7,112)}=24.53, p<0.0001$; interaction: $\left.F_{(10,60)}=7.549, p<0.0001\right)$.

associated memory was generated, on days $5-8$, we switched the sugar-reward from $(+)$-Carvone to $(-)$-Carvone (Fig. $7 A)$ to begin the first reversal learning. Control mice accomplished this task with ease and spent significantly more time digging near the newly associated odorant (-)-Carvone (Fig. 7C), in contrast to the OB-mutant mice (Fig. 7D). The OB-mutant mice's deficits in the flexibility of olfactory association learning and memory were even more apparent in the second reversal memory test, during which they spent nearly equal time digging near both odorants 

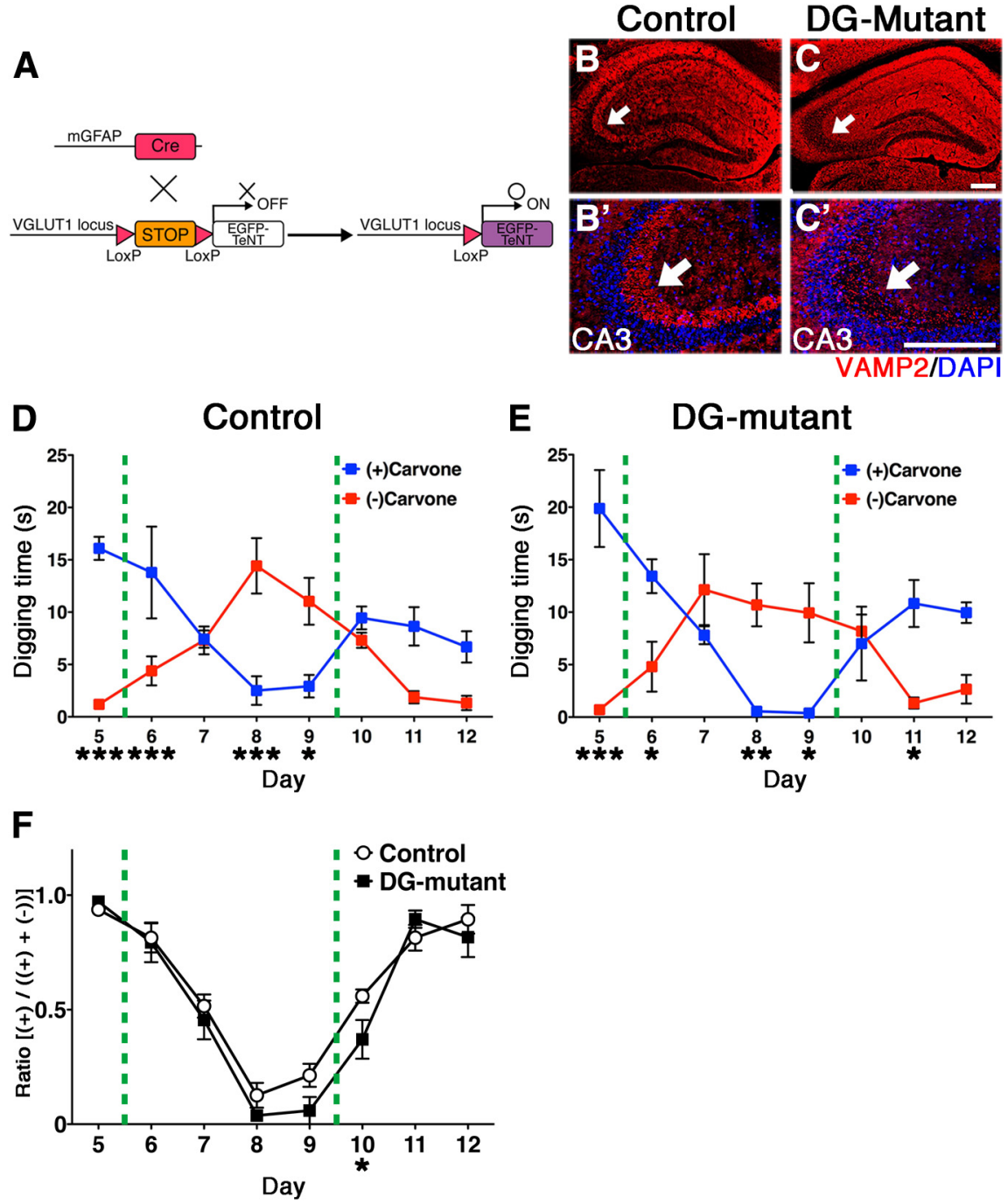

Figure 9. Blocking synaptic transmission of postnatal-born GCs in the hippocampal DG does not affect flexible olfactory associative learning. $A$, Schematic drawing of our genetic strategy to selectively target postnatal-born GCS in the hippocampal DG. Postnatal NSC Cre-driver, mGFAP-Cre mice were crossed with VGLUT1-LoxP-TeNT mice, in which the LoxP-Stop-LoxP-IRES-TeNT gene cassette was knocked into the $3^{\prime}$-noncoding region of the glutamatergic, neuron-specific VGLUT1 gene locus. $B, C$, Hippocampal sections from adult control $(\boldsymbol{B})$ and DG-mutant $(\boldsymbol{C})$ mice stained with anti-VAMP2 antibody (red) and nuclear DAPI (blue). Hippocampal CA3-regions are magnified in $\boldsymbol{B}^{\prime}$ and $\boldsymbol{C}^{\prime}$, respectively. $\boldsymbol{D}, \boldsymbol{E}$, Control $(n=6)$ and $\mathrm{DG}$-mutant $(n=6)$ mice were subjected to the same olfactory associative memory tests shown in Figure $7 A, B$. DG-mutant mice did not exhibit impaired flexible associative olfactory learning and memory. Mean digging times (seconds) \pm SEM during the 4 min probe test period are shown. ${ }^{*} p<0.05 ;{ }^{* *} p<0.01 ;{ }^{* *} p<0.001$; two-way repeated-measures ANOVA of odor and day followed by Fisher's LSD post hoc test (control; odor: $F_{(1,5)}=9.044, p=0.0298$; day: $F_{(7,35)}=1.782, p=0.1222$; interaction: $F_{(7,35)}=19.07, p<0.0001$, DG-mutant: odor: $F_{(1,5)}=4.058, p=0.1142$; day: $F_{(7,35)}=1.754, p=0.1370$; interaction: $\left.F_{(7,35)}=17.87, p<0.0001\right)$. $\boldsymbol{F}$, Ratio was calculated for probe test period using the digging times according to the following formula: $(+)$-carvone/( +$)$-carvone + (-)-carvone). ${ }^{*} p<0.05 ;{ }^{* *} p<0.01 ;{ }^{* * *} p<0.001$; two-way repeated-measures ANOVA of mouse group and day followed by Fisher's LSD post hoc test (group: $F_{(1,10)}=2.966, p=0.1233$; day: $F_{(7,70)}=12.65, p<0.0001$; interaction: $F_{(7,70)}=7.503, p<$ 0.0012). Scale bars, $100 \mu \mathrm{m}$.

(Fig. 7 D, E; days 10-12). Therefore, postnatal-born OB interneurons have critical roles on the flexibility of the olfactory associative learning. In this behavioral analysis, we performed the odorassociated learning and memory test using 3-month-old control and OB-mutant mice; therefore, most GCs, except for superficial/outer GCs, would be silenced according to our fate-mapping results. To analyze more causal relationship between postnatal neurogenesis and flexible olfactory associative learning, we performed the same associative learning tests by using mutant mice in which late-postnatal neurogenesis was acutely ablated by diphtheria toxin fragment A (DT-A) (Fig. 8A,B). To our surprise, we found that these mutant mice having deficits in late-postnatal neurogenesis also showed severe defects in the flexibility of olfactory associative learning and memory (Fig. $8 C-E$ ). These results indicate that ongoing supply of recently generated interneurons has crucial functions for the flexible olfactory associative learning, although embryonically born $\mathrm{OB}$ interneurons are sufficient for simple discrimination of two related odorants and initial acquisition of odor-associated memory. As neurogenesis in the adult hippocampus is also reported to play significant roles in the flexible use of spatially precise learning strategies (Garthe et al., 2009), it is possible that they also contribute to flexible odor-associated learning. To address this, we specifically silenced the postnatal-born DG glutamatergic neurons by generating VGLUT1-LoxPTeNT knock-in mice and crossing them with $m G F A P-C r e$ mice (I.I. and R.K., manuscript in preparation) (Fig. 9A). Here, because newborn neurons in the $\mathrm{OB}$ are GABAergic inhibitory neurons and do not express VGLUT1, they remain intact. VAMP2 immunoreactivity can be used as a criterion for transmission at mossy fiber-CA3 synapses (Nakashiba et al., 2012). VAMP2 immunoreactivity was greatly reduced specifically in mossy fiber terminals of mGFAP-Cre; VGLUT1-LoxPTeNT double transgenic mice (DGmutant), suggesting an inhibition of synaptic transmission of postnatal-born dentate GCs (Fig. 9 B,C). To our surprise, DG-mutant showed no deficits in flexible odor-associated learning and memory (Fig. $9 D-F$ ), indicating that the contribution of DG newborn neurons to flexible olfactory associative learning is minimal. Therefore, continuous postnatal neurogenesis in the SVZ/LV-OB and ongoing supply of newborn interneurons contribute to optimized behaviors in flexible olfactory associative learning.

\section{Discussion}

Most neurons comprising the mammalian CNS are produced during embryogenesis. The vast majority of NSCs switch to give rise or transform to glial cells as brain development proceeds, whereas, in the SVZ of the LV, NSCs are maintained and continue to generate newborn neurons postnatally (Kriegstein and Alvarez-Buylla, 2009). Comprised by a large number of interneurons, this prolonged supply of newborn neurons from the SVZ/LV aids in forming and maintaining the inhibitory $\mathrm{OB}$ network.

Although postnatal-born GCs are preferentially integrated into deep regions of the GCL in the $\mathrm{OB}$, a substantial proportion of embryonic-born GCs are maintained in the outer/superficial regions without replacement (Fig. 2F). Interestingly, it has been 
argued that outer/superficial GCs, whose dendrites target primarily the superficial lamina of the EPL, establish synapses with tufted cells, whereas deep GCs mostly contact the dendrites of mitral cells in the deep lamina of the EPL (Mori et al., 1983; Orona et al., 1983; Shepherd and Greer, 2004; Imamura et al., 2006). Therefore, one interesting possibility is that these two subpopulations fundamentally modulate distinct neural circuits. This, in turn, implies that the activity of tufted cells is under the preferential control of embryonic-born GCs, whereas postnatal-born GCs provide an inhibitory drive to both mitral and tufted cells.

Interestingly, $\mathrm{OB}$ neurogenesis mutant strains tested in this study, the OB-mutant (Fig. 7) and the late-postnatal neurogenesis mutant (Fig. 8), showed severe impairments in flexible olfactory associative learning. These results indicate that continuous postnatal neurogenesis and ongoing supply of newborn interneurons regulate optimized behaviors in flexible olfactory associative learning. Conversely, in these $\mathrm{OB}$ neurogenesis mutant mice, embryonically born $\mathrm{OB}$ interneurons should be normal; therefore, embryonically born OB interneurons are sufficient for simple odor discrimination and initial acquisition of odorassociated memory, although it is possible that postnatal-born new neurons also intensely contribute to these functions in more difficult odor discrimination (Alonso et al., 2012). It is highly desirable to reveal how the differences in anatomical location and turnover rates between embryonically (static, superficial layers) and postnatally (turnover, deep layers) derived GCs contribute to functional dissociations in olfactory-related behaviors. More refined strategies to manipulate these $\mathrm{OB}$ inteneuron populations independently will be required to fully address this notion. In addition to GCs and PGCs, numerous types of GABAergic interneurons have been identified in the OB (Pressler and Strowbridge, 2006; Batista-Brito et al., 2008; Eyre et al., 2008, 2009; Kosaka and Kosaka, 2011; Huang et al., 2013; Kato et al., 2013; Miyamichi et al., 2013), including deep short-axon cells, Blanes cells, and EPL interneurons. Although lineage and turnover analyses of these $\mathrm{OB}$ interneuronal populations have just been started (Batista-Brito et al., 2008), dynamic turnover of these cells by postnatal neurogenesis may also contribute to the reorganization of OB circuitry.

Importantly, it was reported that, shortly after newly generated GCs differentiate and become synaptically integrated, they exhibit long-term synaptic plasticity (Nissant et al., 2009); moreover, this ability is progressively lost as the GCs mature over time, indicating that recently generated, newborn GCs play a more distinct role in the plastic change in the bulber local circuits than more mature counterparts (Nissant et al., 2009). Recently, it was reported that immediate activation of newly generated GCs via channelrhodopsin accelerated difficult odor discrimination learning and improved memory, indicating an immediate causal relationship between the activity of newborn neurons and the function of the OB circuit (Alonso et al., 2012). Strikingly, neurogenesis in the SVZ of the LV occurs throughout adulthood. OB interneurons receive glutamatergic inputs from centrifugal inputs originating from other regions of the brain, such as the olfactory cortex (Shepherd and Greer, 2004; Lazarini and Lledo, 2011; Manabe et al., 2011; Boyd et al., 2012; Breton-Provencher and Saghatelyan, 2012; Markopoulos et al., 2012). Interestingly, long-term synaptic plasticity was selectively observed between centrifugal glutamatergic inputs and recently generated GCs (Nissant et al., 2009). Therefore, the continuous supply of newly generated $\mathrm{OB}$ interneurons allows higher brain areas to participate in the modification of odor detection and value judgment of odor information. Our results demonstrated that the constant arrival of newborn interneurons maintains structural and functional plasticity in the postnatal $\mathrm{OB}$ circuitry. It appears to mediate this plasticity through the highly dynamic formation and elimination of dendrodendritic synapses with principal neurons (mitral and tufted cells), which may play pivotal roles in flexible odor-associated learning processes that require dynamic erasability as well as adaptable consolidation of odor-associated memories.

\section{References}

Adam Y, Mizrahi A (2011) Long-term imaging reveals dynamic changes in the neuronal composition of the glomerular layer. J Neurosci 31:79677973. CrossRef Medline

Ahn S, Joyner AL (2005) In vivo analysis of quiescent adult neural stem cells responding to Sonic hedgehog. Nature 437:894-897. CrossRef Medline

Alonso M, Lepousez G, Wagner S, Bardy C, Gabellec MM, Torquet N, Lledo PM (2012) Activation of adult-born neurons facilitates learning and memory. Nat Neurosci 15:899-904. CrossRef Medline

Anderson JC, Douglas RJ, Martin KA, Nelson JC (1994) Map of the synapses formed with the dendrites of spiny stellate neurons of cat visual cortex. J Comp Neurol 341:25-38. CrossRef Medline

Bagley J, LaRocca G, Jimenez DA, Urban NN (2007) Adult neurogenesis and specific replacement of interneuron subtypes in the mouse main olfactory bulb. BMC Neurosci 8:92. CrossRef Medline

Batista-Brito R, Close J, Machold R, Fishell G (2008) The distinct temporal origins of olfactory bulb interneuron subtypes. J Neurosci 28:3966-3975. CrossRef Medline

Bayer SA (1983) ${ }^{3} \mathrm{H}$-Thymidine-radiographic studies of neurogenesis in the rat olfactory bulb. Exp Brain Res 50:329-340. Medline

Boyd AM, Sturgill JF, Poo C, Isaacson JS (2012) Cortical feedback control of olfactory bulb circuits. Neuron 76:1161-1174. CrossRef Medline

Branda CS, Dymecki SM (2004) Talking about a revolution: the impact of site-specific recombinases on genetic analyses in mice. Dev Cell 6:7-28. CrossRef Medline

Breton-Provencher V, Saghatelyan A (2012) Newborn neurons in the adult olfactory bulb: unique properties for specific odor behavior. Behav Brain Res 227:480-489. CrossRef Medline

Brill MS, Snapyan M, Wohlfrom H, Ninkovic J, Jawerka M, Mastick GS, Ashery-Padan R, Saghatelyan A, Berninger B, Götz M (2008) A dlx2and pax6-dependent transcriptional code for periglomerular neuron specification in the adult olfactory bulb. J Neurosci 28:6439-6452. CrossRef Medline

Egger V, Urban NN (2006) Dynamic connectivity in the mitral cell-granule cell microcircuit. Semin Cell Dev Biol 17:424-432. CrossRef Medline

Eyre MD, Antal M, Nusser Z (2008) Distinct deep short-axon cell subtypes of the main olfactory bulb provide novel intrabulbar and extrabulbar GABAergic connections. J Neurosci 28:8217-8229. CrossRef Medline

Eyre MD, Kerti K, Nusser Z (2009) Molecular diversity of deep short-axon cells of the rat main olfactory bulb. Eur J Neurosci 29:1397-1407. CrossRef Medline

Garcia AD, Doan NB, Imura T, Bush TG, Sofroniew MV (2004) GFAPexpressing progenitors are the principal source of constitutive neurogenesis in adult mouse forebrain. Nat Neurosci 7:1233-1241. CrossRef Medline

Garthe A, Behr J, Kempermann G (2009) Adult-generated hippocampal neurons allow the flexible use of spatially precise learning strategies. PLoS One 4:e5464. CrossRef Medline

Gould E (2007) How widespread is adult neurogenesis in mammals? Nat Rev Neurosci 8:481-488. CrossRef Medline

Huang L, Garcia I, Jen HI, Arenkiel BR (2013) Reciprocal connectivity between mitral cells and external plexiform layer interneurons in the mouse olfactory bulb. Front Neural Circuits 7:32. CrossRef Medline

Ihrie RA, Alvarez-Buylla A (2011) Lake-front property: a unique germinal niche by the lateral ventricles of the adult brain. Neuron 70:674-686. CrossRef Medline

Imamura F, Nagao H, Naritsuka H, Murata Y, Taniguchi H, Mori K (2006) A leucine-rich repeat membrane protein, 5T4, is expressed by a subtype of granule cells with dendritic arbors in specific strata of the mouse olfactory bulb. J Comp Neurol 495:754-768. CrossRef Medline

Imayoshi I, Sakamoto M, Ohtsuka T, Takao K, Miyakawa T, Yamaguchi M, Mori K, Ikeda T, Itohara S, Kageyama R (2008) Roles of continuous 
neurogenesis in the structural and functional integrity of the adult forebrain. Nat Neurosci 11:1153-1161. CrossRef Medline

Imayoshi I, Sakamoto M, Yamaguchi M, Mori K, Kageyama R (2010) Essential roles of Notch signaling in maintenance of neural stem cells in developing and adult brains. J Neurosci 30:3489-3498. CrossRef Medline

Imayoshi I, Sakamoto M, Kageyama R (2011) Genetic methods to identify and manipulate newly born neurons in the adult brain. Front Neurosci 5:64. CrossRef Medline

Imayoshi I, Hirano K, Sakamoto M, Miyoshi G, Imura T, Kitano S, Miyachi H, Kageyama R (2012) A multifunctional teal-fluorescent Rosa26 reporter mouse line for Cre- and Flp-mediated recombination. Neurosci Res 73:78-84. CrossRef Medline

Isaacson JS, Strowbridge BW (1998) Olfactory reciprocal synapses: dendritic signaling in the CNS. Neuron 20:749-761. CrossRef Medline

Kato HK, Gillet SN, Peters AJ, Isaacson JS, Komiyama T (2013) Parvalbumin-expressing interneurons linearly control olfactory bulb output. Neuron 80:1218-1231. CrossRef Medline

Kohwi M, Petryniak MA, Long JE, Ekker M, Obata K, Yanagawa Y, Rubenstein JL, Alvarez-Buylla A (2007) A subpopulation of olfactory bulb GABAergic interneurons is derived from Emx1- and Dlx5/6-expressing progenitors. J Neurosci 27:6878-6891. CrossRef Medline

Kosaka K, Toida K, Aika Y, Kosaka T (1998) How simple is the organization of the olfactory glomerulus? The heterogeneity of so-called periglomerular cells. Neurosci Res 30:101-110. CrossRef Medline

Kosaka T, Kosaka K (2011) "Interneurons" in the olfactory bulb revisited. Neurosci Res 69:93-99. CrossRef Medline

Kriegstein A, Alvarez-Buylla A (2009) The glial nature of embryonic and adult neural stem cells. Annu Rev Neurosci 32:149-184. CrossRef Medline

Lagace DC, Whitman MC, Noonan MA, Ables JL, DeCarolis NA, Arguello AA, Donovan MH, Fischer SJ, Farnbauch LA, Beech RD, DiLeone RJ, Greer CA, Mandyam CD, Eisch AJ (2007) Dynamic contribution of nestin-expressing stem cells to adult neurogenesis. J Neurosci 27:1262312629. CrossRef Medline

Lazarini F, Lledo PM (2011) Is adult neurogenesis essential for olfaction? Trends Neurosci 34:20-30. CrossRef Medline

Lemasson M, Saghatelyan A, Olivo-Marin JC, Lledo PM (2005) Neonatal and adult neurogenesis provide two distinct populations of newborn neurons to the mouse olfactory bulb. J Neurosci 25:6816-6825. CrossRef Medline

Lledo PM, Alonso M, Grubb MS (2006) Adult neurogenesis and functional plasticity in neuronal circuits. Nat Rev Neurosci 7:179-193. CrossRef Medline

Long JE, Garel S, Alvarez-Dolado M, Yoshikawa K, Osumi N, Alvarez-Buylla A, Rubenstein JL (2007) Dlx-dependent and -independent regulation of olfactory bulb interneuron differentiation. J Neurosci 27:3230-3243. CrossRef Medline

Manabe H, Kusumoto-Yoshida I, Ota M, Mori K (2011) Olfactory cortex generates synchronized top-down inputs to the olfactory bulb during slow-wave sleep. J Neurosci 31:8123-8133. CrossRef Medline

Mao J, Barrow J, McMahon J, Vaughan J, McMahon AP (2005) An ES cell system for rapid, spatial and temporal analysis of gene function in vitro and in vivo. Nucleic Acids Res 33:e155. CrossRef Medline

Markopoulos F, Rokni D, Gire DH, Murthy VN (2012) Functional properties of cortical feedback projections to the olfactory bulb. Neuron 76: 1175-1188. CrossRef Medline

Ming GL, Song H (2011) Adult neurogenesis in the mammalian brain: significant answers and significant questions. Neuron 70:687-702. CrossRef Medline

Miyamichi K, Shlomai-Fuchs Y, Shu M, Weissbourd BC, Luo L, Mizrahi A (2013) Dissecting local circuits: parvalbumin interneurons underlie broad feedback control of olfactory bulb output. Neuron 80:1232-1245. CrossRef Medline

Miyoshi G, Hjerling-Leffler J, Karayannis T, Sousa VH, Butt SJ, Battiste J, Johnson JE, Machold RP, Fishell G (2010) Genetic fate mapping reveals that the caudal ganglionic eminence produces a large and diverse popu- lation of superficial cortical interneurons. J Neurosci 30:1582-1594. CrossRef Medline

Mori K, Kishi K, Ojima H (1983) Distribution of dendrites of mitral, displaced mitral, tufted, and granule cells in the rabbit olfactory bulb. J Comp Neurol 219:339-355. CrossRef Medline

Mullen RJ, Buck CR, Smith AM (1992) NeuN, a neuronal specific nuclear protein in vertebrates. Development 116:201-211. Medline

Nakashiba T, Cushman JD, Pelkey KA, Renaudineau S, Buhl DL, McHugh TJ, Rodriguez Barrera V, Chittajallu R, Iwamoto KS, McBain CJ, Fanselow MS, Tonegawa S (2012) Young dentate granule cells mediate pattern separation, whereas old granule cells facilitate pattern completion. Cell 149:188-201. CrossRef Medline

Ninkovic J, Mori T, Götz M (2007) Distinct modes of neuron addition in adult mouse neurogenesis. J Neurosci 27:10906-10911. CrossRef Medline

Nissant A, Bardy C, Katagiri H, Murray K, Lledo PM (2009) Adult neurogenesis promotes synaptic plasticity in the olfactory bulb. Nat Neurosci 12:728-730. CrossRef Medline

Orona E, Scott JW, Rainer EC (1983) Different granule cell populations innervate superficial and deep regions of the external plexiform layer in rat olfactory bulb. J Comp Neurol 217:227-237. CrossRef Medline

Pressler RT, Strowbridge BW (2006) Blanes cells mediate persistent feedforward inhibition onto granule cells in the olfactory bulb. Neuron 49:889904. CrossRef Medline

Rosselli-Austin L, Altman J (1979) The postnatal development of the main olfactory bulb of the rat. J Dev Physiol 1:295-313. Medline

Sakamoto M, Imayoshi I, Ohtsuka T, Yamaguchi M, Mori K, Kageyama R (2011) Continuous neurogenesis in the adult forebrain is required for innate olfactory responses. Proc Natl Acad Sci U S A 108:8479-8484. CrossRef Medline

Sawada M, Kaneko N, Inada H, Wake H, Kato Y, Yanagawa Y, Kobayashi K, Nemoto T, Nabekura J, Sawamoto K (2011) Sensory input regulates spatial and subtype-specific patterns of neuronal turnover in the adult olfactory bulb. J Neurosci 31:11587-11596. CrossRef Medline

Sequerra EB, Miyakoshi LM, Fróes MM, Menezes JR, Hedin-Pereira C (2010) Generation of glutamatergic neurons from postnatal and adult subventricular zone with pyramidal-like morphology. Cereb Cortex 20: 2583-2591. CrossRef Medline

Shepherd GM, Greer CA (2004) Olfactory bulb in the synaptic organization of the brain (Shepherd GM, ed), pp 159-204. New York: Oxford UP.

Srinivas S, Watanabe T, Lin CS, William CM, Tanabe Y, Jessell TM, Costantini $\mathrm{F}$ (2001) Cre reporer strains produced by targeted insertion of EYFP and ECFP into the ROSA26 locus. BMC Dev Biol 1:4. CrossRef Medline

Stenman JM, Rajagopal J, Carroll TJ, Ishibashi M, McMahon J, McMahon AP (2008) Canonical Wnt signaling regulates organ-specific assembly and differentiation of CNS vasculature. Science 322:1247-1250. CrossRef Medline

Stenman J, Toresson H, Campbell K (2003) Identification of two distinct progenitor populations in the lateral ganglionic eminence: implications for striatal and olfactory bulb neurogenesis. J Neurosci 23:167-174. Medline

Winpenny E, Lebel-Potter M, Fernandez ME, Brill MS, Götz M, Guillemot F, Raineteau O (2011) Sequential generation of olfactory bulb glutamatergic neurons by Neurog2-expressing precursor cells. Neural Dev 6:12. CrossRef Medline

Yamaguchi M, Manabe H, Murata K, Mori K (2013) Reorganization of neuronal circuits of the central olfactory system during postprandial sleep. Front Neural Circuits 7:132. CrossRef Medline

Yokoi M, Mori K, Nakanishi S (1995) Refinement of odor molecule tuning by dendrodendritic synaptic inhibition in the olfactory bulb. Proc Natl Acad Sci U S A 92:3371-3375. CrossRef Medline

Yoshihara S, Takahashi H, Nishimura N, Naritsuka H, Shirao T, Hirai H, Yoshihara Y, Mori K, Stern PL, Tsuboi A (2012) 5T4 glycoprotein regulates the sensory input-dependent development of a specific subtype of newborn interneurons in the mouse olfactory bulb. J Neurosci 32:22172226. CrossRef Medline 